\title{
ACC to Dorsal Medial Striatum Inputs Modulate Histaminergic Itch Sensation
}

\author{
Yu-Chen Lu, ${ }^{1,2}$ Yu-Jun Wang, ${ }^{1,2}$ Bin Lu, ${ }^{1,2}$ Ming Chen, ${ }^{3} \odot$ Ping Zheng, ${ }^{3}$ and $\odot$ Jing-Gen Liu ${ }^{1,2}$ \\ ${ }^{1}$ Key Laboratory of Receptor Research, Shanghai Institute of Materia Medica and Collaborative Innovation Center for Brain Science, Chinese Academy of \\ Sciences, Shanghai 201203, China, ${ }^{2}$ University of Chinese Academy of Sciences, Shanghai 200031, China, and ${ }^{3}$ State Key Laboratory of Medical \\ Neurobiology, Collaborative Innovation Center for Brain Science, School of Basic Medical Sciences and Institutes of Brain Science, Fudan University, \\ Shanghai 200032, China
}

Itch is an unpleasant sensation that initiates scratching behavior. The itch-scratch reaction is a complex phenomenon that implicates supraspinal structures required for regulation of sensory, emotional, cognitive, and motivational aspects. However, the central mechanisms underlying the processing of itch and the interplay of the supraspinal regions and spinal cord in regulating itch-scratch processes are poorly understood. Here, we have shown that the neural projections from anterior cingulate cortex (ACC) to dorsal medial striatum (DMS) constitute a critical circuit element for regulating itch-related behaviors in the brains of male C57BL/6J mice. Moreover, we demonstrate that ACC-DMS projections selectively modulate histaminergic, but not nonhistaminergic, itch-related behavior. Furthermore, photoactivation of ACC-DMS projections has also no significant effects on pain behavior induced by thermal, mechanical, and chemical stimuli except for a relief on inflammatory pain evoked by formalin and complete Freund's adjuvant. We further demonstrate that the dorsal spinal cord exerts an inhibitory effect on itch signal from ACC-DMS projections through B5-I neurons, which represent a population of spinal inhibitory interneurons that mediate the inhibition of itch. Therefore, this study presents the first evidence that the ACC-DMS projections modulate histaminergic itch-related behavior and reveals an interplay between the supraspinal and spinal levels in histaminergic itch regulation.

Key words: anterior cingulate cortex; B5-I neurons; brain neural circuit; dorsal medial striatum; itch

\section{Significance Statement}

This study reveals that the projections from anterior cingulate cortex (ACC) to dorsal medial striatum (DMS) constitute a supraspinal circuit for modulation of histaminergic, but not nonhistaminergic, itch. Manipulation of ACC-DMS projections has no effect on acute pain sensation. Furthermore, the dorsal spinal cord exerts an inhibitory effect on itch signal from ACC-DMS projections through B5-I neurons. Understanding the supraspinal itch circuits is of great significance in the development of new therapies for chronic itch-related intractable diseases.

\section{Introduction}

Itch is a complex phenomenon comprising of sensory, cognitive, emotional, and motivational components. Itch is transduced by cutaneous pruriceptors that transmit signals to neurons in the spinal cord via primary afferent sensory neurons with somata located in the dorsal root ganglion (DRG). Cutaneous pruriceptors are

Received Dec. 8, 2017; revised Feb. 25, 2018; accepted March 1, 2018.

Author contributions: Y.-C.L., Y.-J.W., B.L., P.Z., and J.-G.L. designed research; Y.-C.L., Y.-J.W., and M.C. performed research; Y.-C.L., Y.-J.W., and J.-G.L. analyzed data; Y.-C.L., Y.-J.W., and J.-G.L. wrote the paper.

This work was supported by the Ministry of Science and Technology of China (Grants 2013CB835100 and 2015 (B553502 to J.-G.L.), the National Natural Science Foundation of China (Grants 81130087 and 81671322 to J.-G.L. and Grant 81401107 to Y.-J. W.), and the Committee of Science and Technology of Shanghai (Grant $13 J(140680$ to J.-G.L.).

The authors declare no competing financial interests.

Correspondence should be addressed to either Jing-Gen Liu or Yu-Jun Wang, Key Laboratory of Receptor Research,

Shanghai Institute of Materia Medica and Collaborative Innovation Center for Brain Science, Chinese Academy of Sciences, 555 Zu Chong Zhi Road, Shanghai, China 201203; E-mail: jgliu@simm.ac.cn or yjwang@mail.simm.ac.cn.

DOI:10.1523/JNEUROSCI.3466-17.2018

Copyright $\odot 2018$ the authors $\quad 0270-6474 / 18 / 383823-17 \$ 15.00 / 0$ activated by exogenous itch-inducing chemicals, pruritogens, and endogenous pruritogens secreted by epithelial and immune cells (Bautista et al., 2014). Itch can be classified into two subtypes, histaminergic and nonhistaminergic. The former is induced by histamine, which activates histamine receptors; the latter is induced by other pruritogens such as exogenous chloroquine and endogenous 5-hydroxytryptamine (5-HT), which activate nonhistamine receptors (Kim et al., 2008; Liu et al., 2009).

Itch information is initially integrated in the dorsal horn of the spinal cord. The dorsal spinal neurons that express gastrin-releasing peptide receptors (GRPRs) and the natriuretic polypeptide receptor subtype A (NPRA) are required for itch-related behaviors (Sun and Chen, 2007; Sun et al., 2009; Mishra and Hoon, 2013). Ablation of the spinal neurons that express GRPR or NPRA attenuates itch-related behavior in response to a variety of pruritogens (Sun et al., 2009; Mishra and Hoon, 2013). There is also a population of inhibitory interneurons in the dorsal spinal cord termed B5-I neurons that specifically suppress itch signal trans- 
mission (Ross et al., 2010; Kardon et al., 2014). Deletion of B5-I neurons causes self-inflicted skin lesions and results in significantly enhanced scratching responses to pruritic agents (Ross et al., 2010). The kappa opioid dynorphin is a crucial neuromodulator released by B5-I neurons for pruritus (Kardon et al., 2014).

Despite considerable advances made in itch research at the spinal and peripheral levels, the circuits for supraspinal itch modulation and cerebral mechanisms underlying itch-related behavior are poorly understood. Functional brain-imaging studies have shown that itch and scratch processing activates a broad supraspinal structures involved in the regulation of sensory, emotional, cognitive, motivational, and motorial functions (Yosipovitch et al., 2008; Mochizuki and Kakigi, 2015; Mochizuki et al., 2015). Anterior cingulate cortex (ACC), a region described as an interface for motivation, cognition, and action and implicated in encoding reinforcement information to control behaviors (Paus, 2001; Hadland et al., 2003; Matsumoto et al., 2003; Rushworth et al., 2004; Walton et al., 2004), has been consistently reported to be activated in functional imaging studies of itch (Hsieh et al., 1994; Darsow et al., 2000; Drzezga et al., 2001; Mochizuki et al., 2003; Walter et al., 2005; Leknes et al., 2007), suggesting a crucial role of ACC in the processing of itch response.

Scratching an itch activates reward circuits and evokes pleasurable feelings that drive further scratching (Papoiu et al., 2013; Mochizuki et al., 2014, 2015). Therefore, scratching appears to be a reward-motivated or goal-directed behavior. The striatum is a key brain region of the reward circuits. Substantial evidence supports that the goal-directed behavior is encoded by the medial part of dorsal striatum (DMS) (Hollerman et al., 2000; Hassani et al., 2001; Lauwereyns et al., 2002; Delgado et al., 2004; Yin et al., 2005), a component critical in the associative cortico-basal ganglia circuit. In support of an important role of the dorsal striatum, neuroimaging studies have shown that itch and scratch processing activates the dorsal striatum (Herde et al., 2007; Leknes et al., 2007; Vierow et al., 2009; Papoiu et al., 2012; Napadow et al., 2014). Because histamine-induced itch-related behavior simultaneously activates both ACC and the dorsal striatum (Leknes et al., 2007; Vierow et al., 2009; Papoiu et al., 2012), it is thus possible that the ACC and the DMS may be critical components of the neural circuit that processes histaminergic itch-related behavior. The present study, therefore, was undertaken to investigate whether ACC-DMS projections constitute a neural circuit that processes histamine-induced behavior of itch.

\section{Materials and Methods}

Animals. Adult male C57BL/6J mice 6-12 weeks of age and weight 22-26 g were housed in a $12 \mathrm{~h}$ light/dark environment at $21-24^{\circ} \mathrm{C}$. All animal experiments were approved by the National Institutes of Health's Guide for the Care and Use of Laboratory Animals and were approved by the Bioethics Committee of the Shanghai Institute of Materia Medica (Shanghai, China).

Animal behavior tests. Before experiments, mice were allowed $15 \mathrm{~min}$ to acclimate to a chamber. The observation area $(25 \times 25 \mathrm{~cm})$ was surrounded by four mirrors so that a mouse's behaviors could be observed without an obstructed view. Then, the mouse's behaviors were recorded by a digital video camera (C525; Logitech). Investigators were blinded to the treatment condition when assessing videos. One bout of scratching was defined as a lifting of either hindpaw to scratch any part of the body and then replacing it back to the floor. Biting or licking behaviors were assessed using a method from LaMotte et al. (2011). When the recording videos were played back at $1 / 4$ normal speed, the licking behavior could be observed as a sequence of slow head bobs occurring at $\sim 4 \mathrm{~Hz}$, whereas the biting behavior could be observed as a series of gnawing-like movements with little head motion that occurred at $\sim 15 \mathrm{~Hz}$ in which occasional head jerks were interspersed.
Pruritogen-induced itch response. Mice received subcutaneous injection of histamine $(10 \mu \mathrm{g} / \mu \mathrm{l})$, compound 48/80 $(2 \mu \mathrm{g} / \mu \mathrm{l}), 5-\mathrm{HT}(1.5 / 0.3$ $\mu \mathrm{g} / \mu \mathrm{l})$, chloroquine $(4 / 0.8 \mu \mathrm{g} / \mu \mathrm{l})$, or vehicle $(1 \times \mathrm{PBS})$ into the nape of neck with a total volume of $50 \mu$ l. These pruritogens induced intense itch-related scratching behavior for $\sim 30 \mathrm{~min}$. The scratching behavior to the neck was recorded immediately after pruritogen injection and the bouts of scratching were assessed. One bout of scratching was defined as a lifting of either hindpaw to scratch the injection region of body and then replacing it back to the floor. Naive mice were used for each experiment with different pruritogens given.

Cheek model of itch and pain. In the cheek model tests (Shimada and LaMotte, 2008; Akiyama et al., 2010; LaMotte et al., 2011), mice were injected intradermally with histamine $(100 \mu \mathrm{g} / 10 \mu \mathrm{l}$ in PBS), 5-HT (15 $\mu \mathrm{g} / 10 \mu \mathrm{l}$ in PBS), or capsaicin $(10 \mu \mathrm{g} / 10 \mu \mathrm{l}$ in PBS with $20 \%$ ethanol and $7 \%$ Tween 80 ) into the right side of cheek. Pruritogens mainly induce scratching behavior to the cheek, whereas algesic substances primarily cause wiping behavior to the injected site. Scratching behavior consisted of lifting hindpaw to scratch the injection site of the cheek and wiping behavior occurred as a single stroke with the forelimb at the cheek in a caudal to rostral direction. The scratching behavior with hindpaw or wiping behavior by forelimb was recorded for $30 \mathrm{~min}$ immediately after injection. The bouts of scratching or bouts of wiping were assessed.

Calf model of itch and pain. For the calf model (LaMotte et al., 2011) tests, histamine (100 $\mu \mathrm{g} / 10 \mu \mathrm{l}$ in PBS), 5-HT (15 $\mu \mathrm{g} / 10 \mu \mathrm{l}$ in PBS), or capsaicin $(10 \mu \mathrm{g} / 10 \mu \mathrm{l}$ in PBS with $20 \%$ ethanol and 7\% Tween 80$)$ was injected into the skin of the right calf. Pruritogens mostly evoke biting behavior to the calf, whereas algesic substances largely trigger licking behavior to the calf. The biting or licking behavior to the injected site was recorded for $30 \mathrm{~min}$ immediately after injection. As mentioned above, when the recording videos were played back at $1 / 4$ normal speed, the licking behavior could be observed as a sequence of slow head bobs occurring at $\sim 4 \mathrm{~Hz}$, whereas the biting behavior could be observed as a series of gnawing-like movements with little head motion that occurred at $\sim 15 \mathrm{~Hz}$ in which occasional head jerks were interspersed. The duration of biting or licking was assessed.

Itch-related behavior modulation. Lidocaine $(0.3 \%, 200 \mu \mathrm{l})$ was injected subcutaneously into the nape of the neck 10 min before tests. Diphenhydramine (10 mg/kg), JNJ 7777120 (15 mg/kg), or U-50,488 $(2 \mathrm{mg} / \mathrm{kg}$ ) was injected intraperitoneally $30 \mathrm{~min}$ before tests. Intrathecal injections were performed using a method modified from Kardon et al. (2014). Mice were anesthetized by diethyl ether and the hair on the back close to tail was clipped. A $25 \mu \mathrm{l}$ microsyringe with a 30 gauge needle was used for drug delivery and the needle was inserted through the fifth intervertebral space at a $45^{\circ}$ angle until it caused a sudden shaking of the tail. U-50,488 $(10 \mu \mathrm{g} / 5 \mu \mathrm{l})$, nor-binaltorphimine (norBNI; $1 \mu \mathrm{g} / 5 \mu \mathrm{l}$ ), octreotide (3, 10, 30, 100, $300 \mathrm{ng} / 5 \mu \mathrm{l})$, (D-Phe12, Leu14)-bombesin (1, $10 \mathrm{nmol} / 5 \mu \mathrm{l})$, or vehicle $(1 \times \mathrm{PBS}, 5 \mu \mathrm{l})$ was injected over $5 \mathrm{~s}$ and retained for another $10 \mathrm{~s}$; norBNI was injected $24 \mathrm{~h}$ before the test. The mice recovered quickly from anesthesia once the diethyl ether was withdrawn and then received behavioral tests.

Pain tests. For the hotplate test, the mouse was placed on the plate with temperatures of $48^{\circ} \mathrm{C}, 52^{\circ} \mathrm{C}$, or $56^{\circ} \mathrm{C}$ and the latency for it to flick/lick its hindpaw or jump was measured. For the radiant heat test (Xu et al., 2014), a mouse was placed in a Plexiglas holder and its tail was cleaned by $75 \%$ ethanol. One-third of the way down the tail was marked as the stimulating site and the latency for the mouse's tail withdrawal was recorded when a radiant heat stimulation was applied by a thermal sting apparatus (SW-200; Chengdu Taimeng Corporation of Science and Technology). The cutoff time was set as $20 \mathrm{~s}$ to avoid tissue damage. For the paw pressure test (Gong et al., 2009; Xu et al., 2014), the mouse was placed in the Plexiglas holder and then positioned on the electronic pressure apparatus (YLS-3E; Shandong Medical Academy). The right hindpaw received pressure (in grams) stimulation and the pressure was recorded as the mechanical nociceptive threshold when the mouse withdrew its right hindpaw. For the von Frey test, the mouse was placed in an opaque cylinder $15 \mathrm{~min}$ before test. After the mouse was calm, the von Frey filaments were applied to the midplantar area of hindpaw. A filament of $0.02 \mathrm{~g}$ was started and each filament $(0.02,0.04,0.07,0.16,0.4$, $0.6,1.0,1.4 \mathrm{~g}$ ) was applied 5 times until a sudden paw withdrawal, flinch- 
ing, or licking response occurred in 3 of 5 trials. The smallest filament that induced such response was regarded as the paw withdrawal threshold. For the formalin test, 5\% formalin or PBS $(20 \mu \mathrm{l})$ was injected intraplantarly into the left hindpaw. Then, the time spent in licking/ flinching the injected paw was monitored in 5 min intervals for $1 \mathrm{~h}$. The results in acute pain phase $(0-10 \mathrm{~min})$ and inflammatory pain phase (10-60 $\mathrm{min})$ were measured. For the complete Freund's adjuvant (CFA)-induced inflammatory pain test, $20 \mu \mathrm{l}$ of CFA (Sigma-Aldrich) was injected into the plantar area of the left hindpaw. Three hours or $2 \mathrm{~d}$ after CFA injection, the paw withdrawal threshold of both hindpaws was assessed through the von Frey test as described above.

Locomotor activity. Spontaneous locomotor activity of mice was evaluated in an apparatus $(30 \times 30 \times 30 \mathrm{~cm})$ for $30 \mathrm{~min}$. The total distance (in centimeters) traveled was recorded to assess locomotor activity by the program of Laboratory Animal Behavior Analysis System (Anilab), in which the middle point of the mouse body (not including the tail) was tracked to measure the total distance.

Balance beam test. The apparatus of balance beam includes a horizontal flat beam of $12 \mathrm{~mm}$ width and the two ends were fixed $50 \mathrm{~cm}$ above the table. A black box with material from the home cage was settled at one end of the beam as the terminal point. A $60 \mathrm{w}$ lamp was placed at the start point to exert an aversive stimulus. The time for mice to cross $80 \mathrm{~cm}$ of the beam was recorded. This test was conducted over $2 \mathrm{~d}$ of training and $1 \mathrm{~d}$ of test. In the training stage, each mouse was encouraged to cross the beam three times. On the test day, the time of two successful cases in which the mouse crossed the beam without stay was averaged. The beam and box were cleaned with $70 \%$ ethanol and water before the test for next mouse.

BDA tracing. Biotinylated dextran amines (BDAs) are organic compounds that can be used for neuroanatomical tracing. High-molecularweight BDA (10 kDa) could label axons and terminals of neurons anterogradely, whereas low-molecular-weight BDA ( $3 \mathrm{kDa})$ could label cell bodies of neurons retrogradely. BDA $3 \mathrm{k}(10 \%$ in sodium citrate- $\mathrm{HCl}$, $\mathrm{pH} 3)$ or BDA $10 \mathrm{k}(10 \%$ in $1 \times \mathrm{PB})$ with a volume of $0.1 \mu \mathrm{l}$ was used for neural tract tracing. Mice were deeply anesthetized by sodium pentobarbital $(70 \mathrm{mg} / \mathrm{kg}$, dissolved in saline, i.p.) and then put on a stereotaxic instrument (RWD). Small openings ( $1 \mathrm{~mm}$ wide) were made over ACC (AP, $+0.62 \mathrm{~mm}$; ML, $\pm 0.25 \mathrm{~mm}$ ) or DMS (AP, $+0.62 \mathrm{~mm}$; ML, \pm 1.0 $\mathrm{mm}$ ). An injection cannula (33 gauge) was connected to a $10 \mu \mathrm{l}$ microsyringe driven by a microinjection pump (Harvard Apparatus). In anterograde tracing, the ACC region (DV, $-2.0 \mathrm{~mm}$ ) was microinfused with BDA 10k in a speed of $0.05 \mu \mathrm{l} / \mathrm{min}$. The injection cannula was held for additional $10 \mathrm{~min}$ for tracer diffusion. In retrograde tracing, the DMS region $(\mathrm{DV},-2.5 \mathrm{~mm}$ ) was microinfused with BDA $3 \mathrm{k}$ in the same way. Mice were killed $5 \mathrm{~d}$ later to be perfused with saline and then $4 \%$ paraformaldehyde (PFA). Brains were removed and postfixed overnight in $4 \%$ PFA at $4^{\circ} \mathrm{C}$. After being dehydrated in $20 \%$ and $30 \%$ sucrose, the brains were transversely sectioned at $30 \mu \mathrm{m}$ on a cryostat microtome. The coronal brain sections $\sim+0.62 \mathrm{~mm}$ anterior to bregma were picked for staining. One drop of A and B agent (Elite ABC-Peroxidase Kits; Vector Laboratories) was added in $10 \mathrm{ml} 1 \times \mathrm{PB}$ and fully vibrated for at least $30 \mathrm{~min}$, preparing for the $\mathrm{ABC}$ reaction solution. After being rinsed in $1 \times \mathrm{PB}$, brain sections were incubated in $\mathrm{ABC}$ solution for $1 \mathrm{~h}$. Subsequently, the sections were rinsed in $1 \times \mathrm{PB}$ for 3 times and then the labeling was visualized by a DAB (STABLE DAB; Life Technologies) reaction. To enhance the contrast of tracer labeling, the sections were counterstained with Nissl. The BDA-tracing experiments were repeated three times by a different experimenter.

$c$-fos immunostaining. For c-fos detection of ACC (AP, $+0.62 \mathrm{~mm})$ projection neurons, mice received subcutaneous injection of histamine $(500 \mu \mathrm{g} / 50 \mu \mathrm{l})$ or vehicle into the nape of neck 1 week after being microinfused with Fluorogold (FG) (4\% in $1 \times$ PBS, $0.1 \mu \mathrm{l})$ in DMS (AP, $+0.62 \mathrm{~mm}$; ML, $\pm 1.0 \mathrm{~mm}$; DV $-2.5 \mathrm{~mm})$. The mice were deeply anesthetized by sodium pentobarbital ( $70 \mathrm{mg} / \mathrm{kg}$, dissolved in saline, i.p.) and 90 min later perfused with saline and then 4\% PFA. After brains were postfixed, dehydrated, and sectioned in the same way as described for BDA tracing, the coronal brain sections $\sim+0.62 \mathrm{~mm}$ anterior to bregma were selected for c-fos staining. Sections were washed in PBS with $0.3 \%$ TritonX-100 and 3\% normal goat serum for $1 \mathrm{~h}$. Then the sections were incubated in primary antibody (rabbit anti-c-fos, 1:250; Santa Cruz Bio- technology) within PBS (0.3\% Triton X-100 and 3\% normal goat serum) overnight at $4^{\circ} \mathrm{C}$. After being washed $4 \times 10 \mathrm{~min}$ in PBS, the sections were incubated in the secondary antibody (Alexa Fluor 594 goat anti-rabbit, 1:250; Invitrogen) within PBS for $2 \mathrm{~h}$ at room temperature. The sections were then washed three times with PBS and mounted on slides.

For the detection of c-fos induced by pruritogens in the dorsal horn of spinal cord, mice received subcutaneous injection of histamine $(500$ $\mu \mathrm{g} / 50 \mu \mathrm{l}), 5-\mathrm{HT}(75 \mu \mathrm{g} / 50 \mu \mathrm{l})$ or vehicle into the nape of neck. For the c-fos detection evoked by photoactivation of ACC-DMS, the mice expressing enhanced yellow fluorescent protein (EYFP) or EYFP-channelrhodopsin (ChR2) received $30 \mathrm{~min}$ of stimulation-rest cycles ( $3 \mathrm{~min}-$ $2 \mathrm{~min}$, respectively) with a $473 \mathrm{~nm}$ laser on the ACC-DMS pathway. To determine the effect of ACC-DMS photoinhibition on c-fos expression triggered by pruritogens in the dorsal horn, the mice expressing enhanced green fluorescent protein (EGFP) or EGFP-ChR2 received 30 min of stimulation-rest cycles ( $5 \mathrm{~min}-5 \mathrm{~min}$, respectively) with a $532 \mathrm{~nm}$ laser immediately after being subcutaneously injected with histamine (500 $\mu \mathrm{g} / 50 \mu \mathrm{l}$ ), 5-HT (75 $\mu \mathrm{g} / 50 \mu \mathrm{l})$, or vehicle into the nape of neck. The mice were deeply anesthetized by sodium pentobarbital $(70 \mathrm{mg} / \mathrm{kg}$, dissolved in saline, i.p.) $90 \mathrm{~min}$ later and then perfused with saline and then $4 \%$ PFA. The L2-L3 segment of the spinal cord was removed and postfixed for $2 \mathrm{~h}$ in $4 \%$ PFA. The segments of spinal cord were then sectioned in the same way as before and washed in PBS with $0.3 \%$ Triton X-100 and $3 \%$ normal goat serum for $1 \mathrm{~h}$. The sections were then incubated in primary antibody (rabbit anti-c-fos, 1:1000; Santa Cruz Biotechnology) in PBS $\left(0.3 \%\right.$ Triton X-100 and $3 \%$ normal goat serum) overnight at $4^{\circ} \mathrm{C}$. After being washed $4 \times 10 \mathrm{~min}$ in PBS, the sections were incubated in the secondary antibody (Alexa Fluor 594 goat anti-rabbit, 1:1000; Invitrogen) in PBS for $2 \mathrm{~h}$ at room temperature. The sections were then washed three times with PBS and mounted on slides. The antibodies applied here were validated in the instructions for users or certificate of analysis.

ACC-DMS disconnection. Mice were deeply anesthetized by sodium pentobarbital $(70 \mathrm{mg} / \mathrm{kg}$, dissolved in saline, i.p.) and then put on a stereotaxic instrument (RWD). An injection cannula (33 gauge) was connected to a $10 \mu \mathrm{l}$ microsyringe driven by a microinjection pump (Harvard Apparatus). Small openings were made above the right side of ACC (AP, $+0.62 \mathrm{~mm}$; ML, $+0.25 \mathrm{~mm}$ ) and the left side of DMS (AP, $+0.62 \mathrm{~mm}$; ML, $-1.0 \mathrm{~mm}$ ). Mice were infused with quinolinic acid (15 $\mu \mathrm{g} / \mu \mathrm{l}, 0.2 \mu \mathrm{l}$ ), one side into the right ACC (AP, $+0.62 \mathrm{~mm}$; ML, +0.25 $\mathrm{mm}$; DV,$-2.0 \mathrm{~mm}$ ) and the other side into the left DMS (AP, +0.62 $\mathrm{mm}$; ML, $-1.0 \mathrm{~mm}$; DV, $-2.5 \mathrm{~mm}$ ) at a rate of $0.2 \mu \mathrm{l} / \mathrm{min}$ and then retained for 5 more minutes to ensure drug diffusion. After $7 \mathrm{~d}$ recovering from surgery, the mice received subcutaneous injection of histamine $(10 \mu \mathrm{g} / \mu \mathrm{l}$ in saline, $50 \mu \mathrm{l}), 5$-HT $(1.5 \mu \mathrm{g} / \mu \mathrm{l}$ in saline, $50 \mu \mathrm{l})$, or vehicle (saline, $50 \mu \mathrm{l}$ ) into the nape of neck and the scratching bouts were recorded for $30 \mathrm{~min}$ in $5 \mathrm{~min}$ intervals. All mice were killed after the test and the brains were sectioned for Nissl's staining to verify neural lesion.

Virus injection. The adeno-associated viruses (AAVs) were packaged as AAV8 by HeYuan Biotechnological. The virus vector was driven by CaMkII $\alpha$ promoter, which could be expressed selectively in excitatory neurons rather than inhibitory interneurons in the cortex (Tye et al., 2011). Mice were deeply anesthetized with sodium pentobarbital (70 $\mathrm{mg} / \mathrm{kg}$, dissolved in saline, i.p.) and then fixed in a stereotaxic apparatus. Small openings $(1 \mathrm{~mm})$ were made above the left ACC (AP, +0.62 mm; $\mathrm{ML},-0.25 \mathrm{~mm}$ ) and the same side of DMS (AP, +0.62 mm; ML, -1.0 $\mathrm{mm}$ ). An injection cannula (33 gauge) was connected to a $10 \mu \mathrm{l}$ microsyringe driven by microinjection pump (Harvard Apparatus). In optical activation experiments, neurons with expression of ChR2 could be activated by $473 \mathrm{~nm}$ laser illumination. The ChR2 was given in conjunction with EYFP. The mice were microinjected with $0.8 \mu$ l of AAV8-CaMkII $\alpha$ ChR2-EYFP or AAV8- CaMkII $\alpha$-EYFP (titer: $4.26 \times 10^{12} \mathrm{vg} / \mathrm{ml}$ ) into the left ACC (AP, $+0.62 \mathrm{~mm}$; ML, $-0.25 \mathrm{~mm}$; DV,$-2.0 \mathrm{~mm}$ ) at a rate of $0.1 \mu \mathrm{l} / \mathrm{min}$ and remained for additional $10 \mathrm{~min}$ to ensure virus diffusion. Next, a fiber optic [200 $\mu \mathrm{m}$ diameter; numerical aperture (NA) 0.37] was implanted above the left DMS (AP, $+0.62 \mathrm{~mm}$; ML, $-1.0 \mathrm{~mm}$; DV, $-2.25 \mathrm{~mm}$ ) and secured to the skull by dental cement. In optical inhibition experiments, neurons expressing archaerhodopsin- $\mathrm{T}$ (ArchT) could be inhibited by $532 \mathrm{~nm}$ laser illumination. The ArchT was linked with EGFP. Mice were bilaterally (AP, $+0.62 \mathrm{~mm}$; ML, $\pm 0.25 \mathrm{~mm}$; DV,-2.0 
$\mathrm{mm}$ ) microinjected with $0.6 \mu$ l of AAV8 (AAV-CaMK2 $\alpha$-ArchT-EGFP, $\left.9.24 \times 10^{12} \mathrm{vg} / \mathrm{ml}\right)$ into ACC in the same way. Then, the fiber optics $(200$ $\mu \mathrm{m}$ diameter; NA 0.37 ) were implanted bilaterally above DMS (AP, $+0.62 \mathrm{~mm}$; ML, $\pm 1.0 \mathrm{~mm}$; DV,$-2.25 \mathrm{~mm}$ ) and secured to the skull by dental cement. The opening of skull skin was cemented by tissue adhesive (Vetbond Tissue Adhesive; $3 \mathrm{M}$ ). In all experiments, the mice received tests at least 4 weeks after surgery.

Optical stimulation. The implanted fiber optic was connected to a fibercoupled laser source (adjustable power: 0-100 mW; Anilab) through a rotatory joint patch cable (FC-M200 $\mu$ m; NA 0.37; Anilab). Optical stimulation was controlled with stimulus generator software (AniOptover 2.0) via a computer. In optical activation tests, mice received $473 \mathrm{~nm}$ light stimulation ( $5 \mathrm{~mW}, 20 \mathrm{~Hz}, 5 \mathrm{~ms}$ pulses) for $3 \mathrm{~min}$ and then rested for 2 min without light stimulation. We defined this stimulation-rest as one $\mathrm{S}-\mathrm{R}$ cycle $(5 \mathrm{~min})$. After mice accepted two $\mathrm{S}$-R cycles $(10 \mathrm{~min})$, four S-R cycles $(20 \mathrm{~min})$, or six S-R cycles $(30 \mathrm{~min})$, the scratching or biting behavior were recorded for $60 \mathrm{~min}$. In optical inhibition tests for the itch model of the neck, mice received injections of different pruritogens including histamine $(10 \mu \mathrm{g} / \mu \mathrm{l})$, compound 48/80 $(2 \mu \mathrm{g} / \mu \mathrm{l}), 5$-HT $(1.5 / 0.3$ $\mu \mathrm{g} / \mu \mathrm{l})$, chloroquine $(4 / 0.8 \mu \mathrm{g} / \mu \mathrm{l})$, and vehicle $(1 \times \mathrm{PBS})$ into the nape of neck with a total volume of $50 \mu \mathrm{l}$ and the scratching behavior to the neck was recorded for $30 \mathrm{~min}$. In optical inhibition tests for the cheek model and the calf model, mice were injected intradermally with histamine (100 $\mu \mathrm{g} / 10 \mu \mathrm{l}$ in PBS), 5-HT (15 $\mu \mathrm{g} / 10 \mu \mathrm{l}$ in PBS), or capsaicin (10 $\mu \mathrm{g} / 10 \mu \mathrm{l}$ in PBS with $20 \%$ ethanol and $7 \%$ Tween 80 ) into the skin of the cheek or calf and the behaviors were assessed in the following $30 \mathrm{~min}$. The total recording time of $30 \mathrm{~min}$ was divided into 65 -min intervals, with cycles of 15 -min interval without light stimulation and then an interval of constant light stimulation ( $5 \mathrm{~mW}$ ) at $532 \mathrm{~nm}$ for $5 \mathrm{~min}$. Because the rate of success for surgery is $\sim 80 \%$, all mice were killed and the brains were sectioned to verify an appropriate virus expression and optical fiber implantation after the behavioral tests. In some cases, the virus may have extended to the nearby regions and these data were excluded from further analysis.

In vitro electrophysiology by optogenetic approach. At least 4 weeks after AAV virus injection, mice were anesthetized with chloral hydrate $(400$ $\mathrm{mg} / \mathrm{kg}$, i.p.). The brain was removed rapidly and fixed in modified ACSF containing the following (in mM): $88 \mathrm{NaCl}, 25 \mathrm{NaHCO}_{3}, 7 \mathrm{MgCl}_{2}, 2.5$ $\mathrm{KCl}, 1.25 \mathrm{NaH}_{2} \mathrm{PO}_{4}, 0.5 \mathrm{CaCl}_{2}$, and 75 sucrosesaturated with $95 \% \mathrm{O}_{2}$ and $5 \% \mathrm{CO}_{2}$ at $\sim 0^{\circ} \mathrm{C}$. Slices of $250 \mu \mathrm{m}$ containing ACC and DMS were cut on a vibratome (VT-1200; Leica) and transferred to normal ACSF containing the following (in mM): $126 \mathrm{NaCl}, 25 \mathrm{NaHCO}_{3}, 2.5 \mathrm{KCl}, 2.5 \mathrm{CaCl}_{2}, 2$ $\mathrm{MgSO}_{4}, 1.25 \mathrm{NaH}_{2} \mathrm{PO}_{4}$, and 10 glucose for incubation at $32^{\circ} \mathrm{C}$ for at least $60 \mathrm{~min}$ before patch-clamp recording. Neurons were visualized on an upright microscope (BX50WI; Olympus) by infrared differential interference contrast or fluorescent optics and whole-cell voltage-clamp or current recordings were conducted through an EPC10 amplifier and Patch Master 2.54 software (HEKA). Electrodes filled with patch pipette solution containing the following (in $\mathrm{mM}$ ): $130 \mathrm{~K}$-gluconate, $10 \mathrm{HEPES}$, $8 \mathrm{NaCl}, 2 \mathrm{ATP} \cdot \mathrm{Mg}$, 0.6 EGTA, $0.1 \mathrm{CaCl}_{2}$, and $0.1 \mathrm{GTP} \cdot \mathrm{Na}_{3}, \mathrm{pH} 7.4$, with a resistance of 3-4 M $\Omega$. Action potential was recorded when cells were held at $0 \mathrm{pA}$ under a current-clamp mode and EPSC was recorded when cells were held at $-70 \mathrm{mV}$ under a voltage-clamp mode. Series resistance compensation was not used, but cells in which $R_{\mathrm{s}}$ changed by $>15 \%$ were discarded. Neurons expressing ChR2-EYFP were stimulated by a $473 \mathrm{~nm}$ light $(5 \mathrm{~mW})$ with $5 \mathrm{~ms}$ width at $20 \mathrm{~Hz}$ and neurons expressing ArchT-EGFP were illuminated by a constant light at $532 \mathrm{~nm}(5 \mathrm{~mW})$ delivered through an optical fiber (core diameter $200 \mu \mathrm{m}$, NA 0.37) connected to a laser source (Anilab) and the end of the fiber optic was placed $500 \mu \mathrm{m}$ above the recording cell.

Statistical analysis. The number of animals for each group was determined according to numbers reported in published studies for justification of sample size and the accurate animal numbers are given in figure legends. Given the randomization of experiments, animals from different experimental groups were allocated to each cage.

Statistical tests were performed with GraphPad Prism 7 software for Windows. Single-variable differences were analyzed by two-tailed and unpaired Student's $t$ tests. Grouped differences were analyzed with oneway or two-way ANOVA followed by Bonferroni posttests. Normal probability plot was applied to detect the normality of data. The estimates of variance within each group were included in the results of analysis from the Prism software. All data are represented as the mean \pm SEM and error bars in the figures indicate SEM. $p<0.05$ was considered statistically significant.

\section{Results}

Neurons projecting to the DMS from the ACC are involved in modulation of histamine-induced itch response

There are reciprocal neural projections between the ACC and the dorsal striatum in the primate (Kunishio and Haber, 1994; Morecraft and Van Hoesen, 1998). To test whether the reciprocal neural projections between the ACC and the DMS also occur in mice, we first conducted neural tract tracing experiments with BDAs. Figure $1 A$ is a schematic depiction of neural projections from ACC to DMS. Abundant tracer signals were detected in the ACC when retrograde tracer BDA $3 \mathrm{k}$ was injected into the DMS (Fig. $1 B$, left), whereas robust tracer signals were detected in the DMS when anterograde tracer BDA 10k was injected into the ACC (Fig. $1 B$, right). This indicates that the ACC has neural projections into the DMS.

Next, we investigated whether ACC-DMS projections were activated by itch stimulation. We used FG retrograde tracing combined with $\mathrm{c}$-fos immunohistochemistry to determine whether histamine-induced c-fos expression was located in the projection neurons. When histamine was injected subcutaneously into the neck region to induce itch responses, enhancement of c-fos expression, labeled by FG retrograde tracing from DMS, was observed in the ACC (Fig. 1C,D), suggesting that histamine activated the neurons projected from the ACC to the DMS. Next, we investigated whether ACC-DMS projections were involved in modulating itch sensation. To disrupt intrahemispheric neural communication bilaterally between the ACC and DMS, we produced lesions of ACC in the right hemisphere and DMS in the left hemisphere using quinolinic acid (Fig. 1E). ACC lesions primarily encompassed cingulated cortex 1 and 2 area and DMS lesions were mostly confined to the area close to the lateral ventricle, which were confirmed by Nissl staining and immunostaining for the neuronal marker NeuN (data not shown). We found that ACC-DMS circuit disconnection by unilateral lesion of ACC plus contralateral lesion of DMS resulted in a significant reduction of histamine-induced, but not 5-HT-induced, scratching behavior (Fig. $1 F$ ), whereas these mice exhibited normal locomotor activity and motor balance/coordination (data not shown). These results suggest that ACC-DMS projections play a key role in modulation of histamine-induced, but not non-histamine-induced, scratching behavior. In addition, we examined some somatosensory- and emotion-related cerebral nuclei and found that histamine stimulation did not change c-fos expression level in the primary/secondary somatosensory cortex (S1/2) and emotion-related brain regions including the central nucleus and the basolateral amygdala of amygdala subnuclei, but increased c-fos expression in the prefrontal cortex (Fig. 2), a brain region required for goal-directed or motivated behavior (Cardinal et al., 2002).

A body of evidences suggests that the neural pathways and molecular mechanisms responsible for processing of itch and pain are overlapping (Ikoma et al., 2006; Davidson and Giesler, 2010; Bautista et al., 2014). To test whether ACC-DMS projections were also involved in modulation of pain, we therefore examined the effect of unilateral lesion of ACC plus contralateral lesion of DMS on pain responses. The results show that the mice with ACC-DMS circuit disconnection exhibited normal pain responses in von Frey test of mechanical pain (Fig. 3A), radiant heat test of thermal pain (Fig. 3B), and capsaicin test of chemical pain (Fig. 3C). 
A

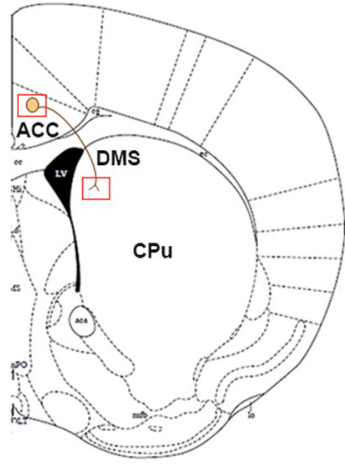

C
B

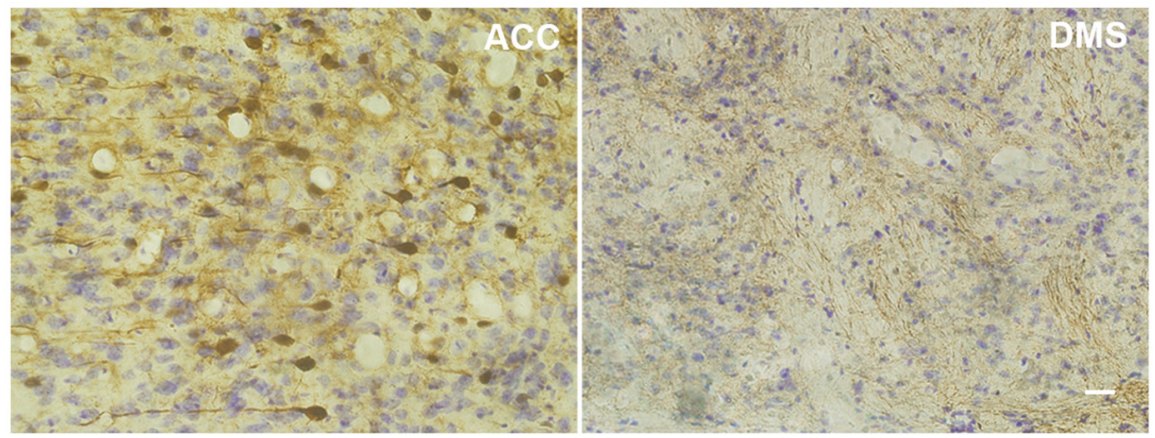

Fluorogold

c-fos

Merge
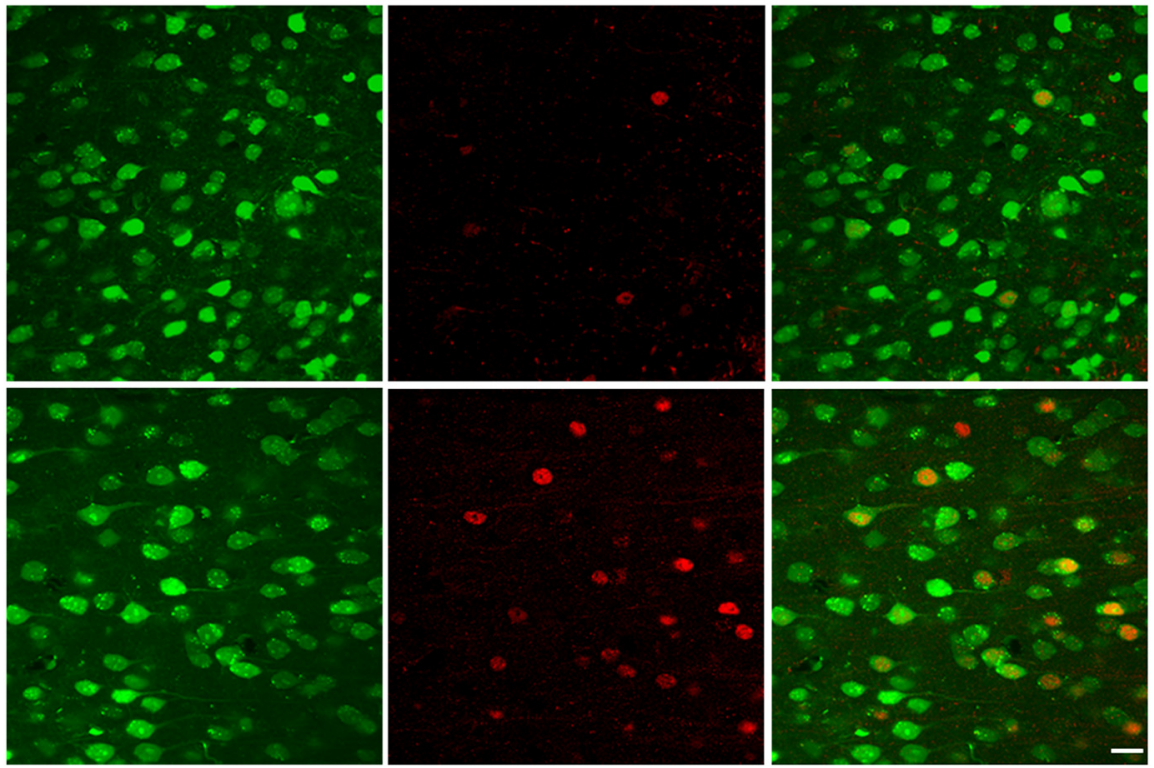

F
D

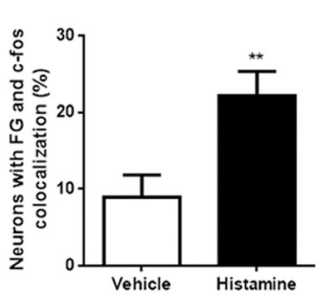

E

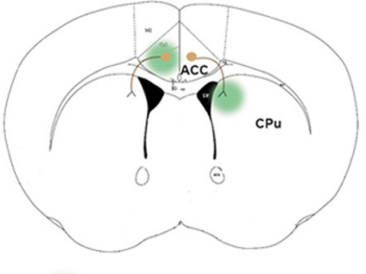

QA lesion area
Figure 1. Neuronal projections from ACC to DMS are involved in modulation of histamine-induced itch. $A$, Schematic depiction of neural projection from ACC to DMS. $B$, ACC neurons project to DMS revealed by tract tracing with BDA. Left, Tracer signals in ACC by BDA 3k retrograding from DMS. Right, Tracer signals in DMS by BDA 10k anterograding from ACC. The images were achieved from coronal brain sections around $+0.62 \mathrm{~mm}$ anterior to bregma. Scale bar, $50 \mu \mathrm{m}$. C, D, c-fos immunostaining in FG-labeled ACC-DMS projections in response to histamine-induced itch. C, Representative immunostaining images of c-fos in FG-labeled ACC-DMS projections. FG was microinjected into DMS and the neurons in ACC was labeled by FG retrograding from DMS. D, Quantification of immunostaining images of $c$-fos in the total neurons labeled by FG. $t_{(12)}=3.078, p=0.0096$. Student's $t$ test. $E$, $F$, Disconnection of ACC and DMS projections with quinolinic acid attenuated histamine-induced, but not 5 -HT-induced, itch. E, Schematic illustration of contralateral lesions of ACC and DMS. F, Scratching behavior induced by subcutaneous injection of histamine (500 $\mu \mathrm{g} / 50$ $\mu$ l) rather than 5 -HT $(75 \mu \mathrm{g} / 50 \mu \mathrm{l})$ into the nape of neck was significantly decreased by disconnection of ACC-DMS circuit. Histamine: interaction, $F_{(5,80)}=2.49$; time, $F_{(5,80)}=18.38 .5-\mathrm{HT}$ : interaction, $F_{(5,70)}=0.1175 ;$ time, $F_{(5,70)}=13.29$. Two-way ANOVA. All data are shown as mean \pm SEM. ${ }^{*} p<0.05,{ }^{* *} p<0.01,{ }^{* * *} p<0.001$ compared with vehicle or disconnection group. $n=$ $8-10$ mice for each group. 
A

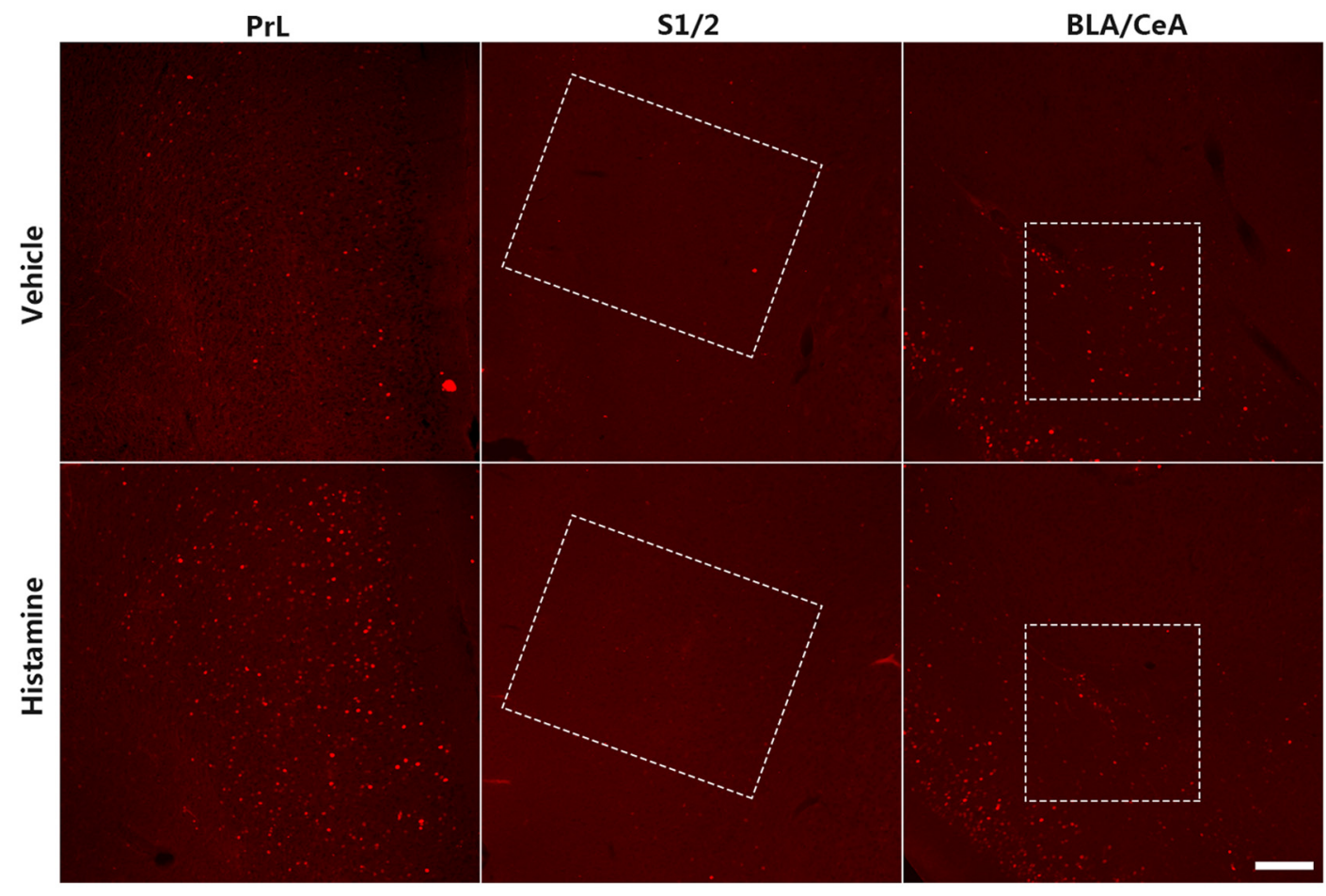

B

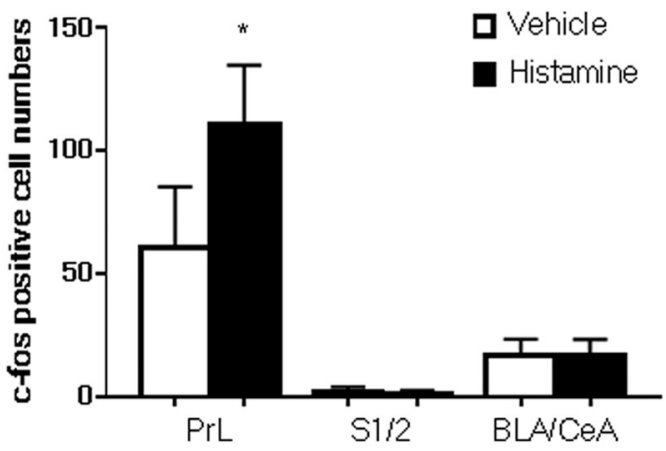

Figure 2. c-fos expression in prelimbic cortex, somatosensory cortex, and amygdala after histamine stimulation. $A$, Mice were subcutaneously injected with histamine ( $500 \mu$ g $/ 50 \mu l)$ or vehicle (saline, $50 \mu \mathrm{l}$ ) and c-fos expression was detected in the prefrontal cortex (PrL) (AP +1.98 mm), S1/2 (AP +0.62 mm), and basolateral amygdala (BLA)/central nucleus (CeA) (AP -1.22 $\mathrm{mm})$. B, The PrL was found to have increased c-fos expression after histamine stimulation. Scale bar, $200 \mu \mathrm{m}$. PrL: $t_{(8)}=0.0127$. S1/2: $t_{(8)}=0.05091$. BLA/CeA: $t_{(8)}=0.9999$. Data are shown as mean \pm SEM. ${ }^{*} p<0.05$ compared with vehicle group, Student's $t$ test. $n=5$ mice for each group.

\section{Optogenetic activation of ACC-DMS projections evokes histamine-related itch responses}

Optogenetics is the powerful approach for investigating neural circuits underlying complex animal behaviors with high temporal and spatial precision (Zhang et al., 2007, 2010). We therefore used an optogenetic approach to confirm the role of ACC-DMS projections in modulation of histaminergic itch responses. Mice were injected with AAV carrying a gene encoding ChR2 in conjunction with EYFP into ACC and optic fiber was implanted over DMS (Fig. 4A). Four weeks after injection, EYFP expression was seen in ACC cell bodies and axons projecting to DMS (Fig. 4B), which indicated targeting of ACC-DMS projections. We next investigated the electrophysiological properties of optogenetically driven terminal stimulation in this circuit using whole-cell recordings. In vitro electrophysiological recordings in slices demonstrated that illumination of ACC terminals in DMS by $473 \mathrm{~nm}$ laser elicited highfidelity spiking in ACC (Fig. 4C) and EPSCs in the DMS neuron (Fig. $4 D$ ), indicating that photostimulation of ACC-DMS projections drives reliable neural transmission.
In the behavioral tests, to activate ACC-DMS projections effectively and avoid the damage to brain tissue caused by long lasting illumination, we set the stimulation pattern as cycles of photoillumination for 3 min with 2 min intervals of rest (Fig. 4E). Illumination of ACC-DMS projections for a short time (10 min or $20 \mathrm{~min}$ of total cycle time) failed to produce significant increase in scratching behavior (data not shown), whereas illumination of ACC-DMS projections for a longer time (30 min of total cycle time) induced a significant enhancement of scratching behavior (Fig. 4F, G, Movie 1) without altering locomotion and motor balance/coordination (data not shown). The mice scratched bilateral regions of body including head, neck, and abdomen. Next, we investigated whether photoactivation-induced scratching behavior was due to itch sensation. To do this, we used lidocaine to block sensory input from primary sensory neurons (Holstege et al., 2008; Ross et al., 2010). We found that blockade of sensory input by subcutaneous injection of lidocaine into the nape of neck remarkably attenuated the scratching behavior (Fig. $4 H$ ). Moreover, we demonstrated that the abnormal scratching behavior was also greatly inhib- 
A von Frey (Left)

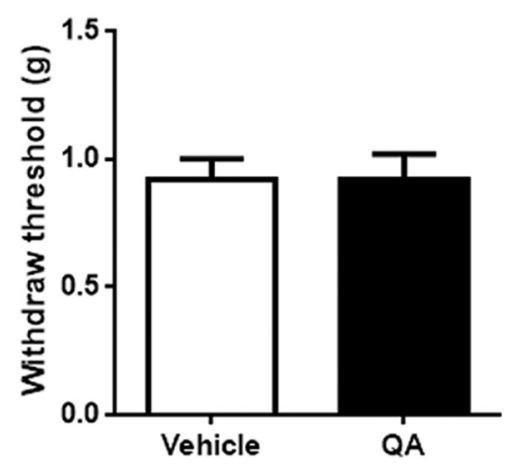

B

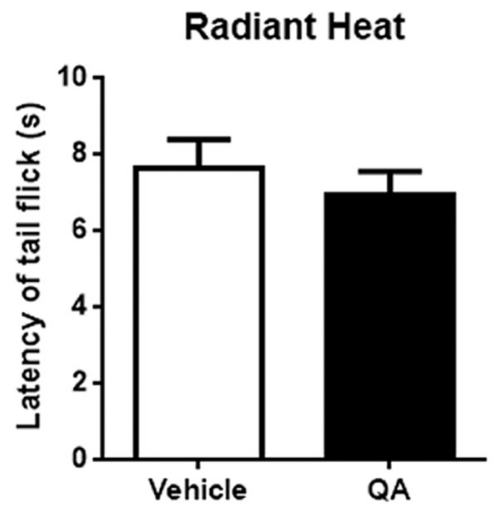

von Frey (Right)

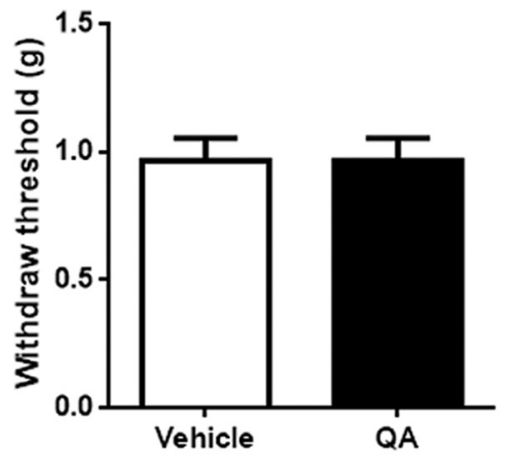

C

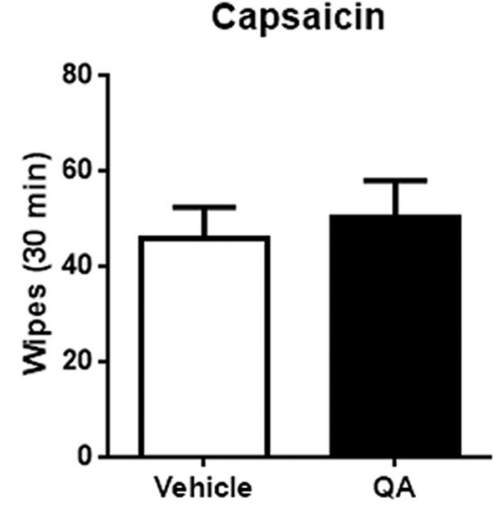

Figure 3. ACC-DMS disconnection has no influence on acute nociceptive sensation of mice. $\boldsymbol{A}$, Mice with ACC-DMS disconnection exhibited normal mechanical pain response in von Frey test. Left, $t_{(18)}=0$. Right, $t_{(18)}=0 ; p>0.9999$. The bilateral hindpaws were examined. $B$, Mice with ACC-DMS disconnection displayed comparable heat pain response in the radiant heat test. $t_{(14)}=$ $0.6884, p=0.5024$. C, No significant difference of capsaicin-induced chemical pain was observed in mice with ACC-DMS disconnection. Capsaicin $(10 \mu \mathrm{g} / 10 \mu \mathrm{l})$ was intradermally injected into the right side of the cheek. $t_{(14)}=0.4438, p=0.6640$. All data are shown as mean \pm SEM. $p>0.05$ compared with vehicle groups, Student's $t$ test. $n=8-10$ mice for each group.

planted above DMS (Fig. 5A). Four weeks after injections, mice expressing ArchTEGFP in the ACC displayed intensive EGFP in the DMS (Fig. 5B). Illumination of ACC terminals in DMS with $532 \mathrm{~nm}$ laser dramatically inhibited ACC somata spiking (Fig. $5 C$ ), demonstrating a specific antidromic inhibition.

For the itch-related behavior tests, we set the stimulation pattern as cycles of photoillumination for $5 \mathrm{~min}$ with $5 \mathrm{~min}$ intervals of rest (Fig. 5D). Mice were injected subcutaneously with histamine (500 $\mu \mathrm{g} / 50 \mu \mathrm{l})$, compound 48/80(100 $\mu \mathrm{g} / 50 \mu \mathrm{l})$, and the nonhistamine pruritogens chloroquine $(200 \mu \mathrm{g} / 50 \mu \mathrm{l})$ and 5 -HT $(75$ $\mu \mathrm{g} / 50 \mu \mathrm{l})$ into the nape of neck $5 \mathrm{~min}$ before received delivery of laser (532 nm) to the DMS and scratching behaviors were recorded for $30 \mathrm{~min}$ with cycles of lights off and lights on. Illumination of ACC terminals in DMS with $532 \mathrm{~nm}$ laser significantly inhibited scratching behavior induced by histamine (Fig. 5E) and compound $48 / 80$ (Fig. $5 F$ ), a compound that stimulates mast cells to release histamine (Kuraishi et al., 1995). However, the same illumination had no inhibitory effect on chloroquine- and 5-HT-induced scratching behavior (Fig. 5G,H). To exclude that the failure of inhibition of chloroquine- and 5-HT-induced scratching by illumination was due to inappropriate high doses used, we thus examined the effect of photoinhibition of ACC-DMS projections with a lower dose of chloroquine $(40 \mu \mathrm{g} / 50 \mu \mathrm{l})$ - and 5-HT ( $15 \mu \mathrm{g} / 50 \mu \mathrm{l})$-induced scratching behavior. Illumination of ACC terminals in

ited by intraperitoneal injection of histamine-1 receptor antagonist diphenhydramine or histamine-4 receptor antagonist JNJ 7777120 (Fig. 4I,J; Dunford et al., 2007; Thurmond et al., 2008; Davidson and Giesler, 2010). In addition, photoactivation of ACC-DMS projections also gave rise to significant increase in biting behavior to bilateral regions of body (including the back near the tail and hindlimbs) as early as after a $10 \mathrm{~min}$ stimulation-rest cycle and after a $30 \mathrm{~min}$ stimulation-rest cycle (Fig. $4 K, L$, Movie 2) and such behavior was suppressed by a lidocaine and a histamine-1 receptor antagonist (Fig. $4 M, N$ ) as well, suggesting that biting behavior was also indicative of the itch response (Akiyama et al., 2010; LaMotte et al., 2011). These findings strongly suggest that photoactivation of ACC-DMS projections evokes histaminergic itch-related behaviors.

\section{Optogenetic inhibition of ACC inputs to the DMS reduces histamine-induced, but not nonhistamine pruritogen-induced, itch responses}

To further verify the role of ACC-DMS projections in the modulation of histaminergic itch responses, we next determined the effect of optogenetical inhibition of the ACC-DMS projections on various pruritogen-induced behaviors of itch. Toward this end, we bilaterally injected the AAV carrying the gene encoding the inhibitory opsin ArchT linked to EGFP into ACC (Chow et al., 2010; Mattis et al., 2011), whereas control animals received the same viral vector carrying EGFP alone. Optical fibers were bilaterally im-
DMS with $532 \mathrm{~nm}$ laser also failed to inhibit, at the lower dose of the two drugs, the induced scratching behavior (data not shown). Scratching the cheek with the hindlimb and biting the skin of the calf are indicative of itch sensation in the cheek and the calf models, respectively (Shimada and LaMotte, 2008; Akiyama et al., 2010; LaMotte et al., 2011). To further confirm that ACC-DMS projections are not implicated in modulation of itch induced by nonhistamine pruritogens, we next tested the effects of photoinhibition of ACC-DMS projections on 5-HT-induced scratching of the cheek using the cheek model and 5-HT-induced biting of the skin of the calf using the calf model. We found that photoinhibition of ACC-DMS projections had no significant effects on 5-HTinduced scratching the cheek and biting the skin of the calf (Fig. $5 I, J)$. Together, these findings indicate that ACC-DMS projections mediate histamine-induced, but not nonhistamine pruritogeninduced, scratching behaviors.

c-fos expression is differently induced by histamine and 5-HT in the ACC and suppressed by photoinhibition of ACC-DMS projections in the dorsal horn

The c-fos gene is commonly used as a marker of neuronal activity to map the neural substrates that are recruited by various stimuli. To determine why itch-related behavior induced by histamine and nonhistamine pruritogens are modulated differently by ACCDMS projections, we investigated whether histamine and 5-HT 
A

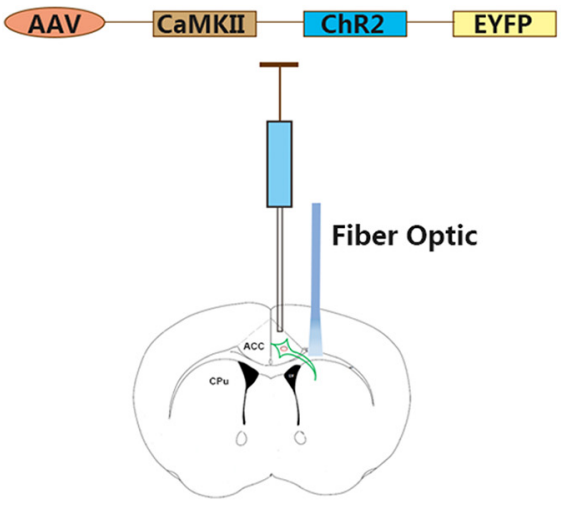

C

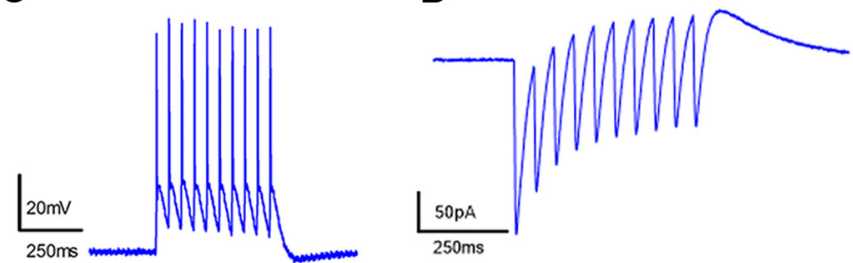

E

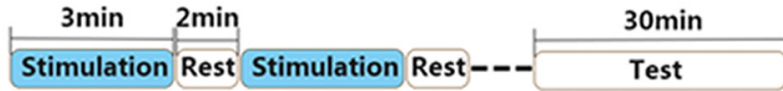

G

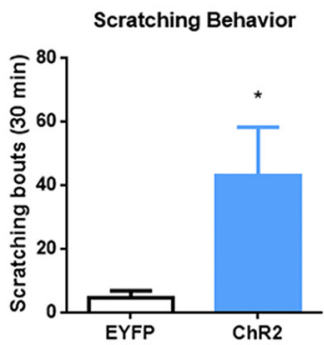

K

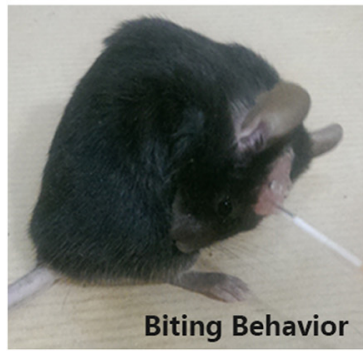

H

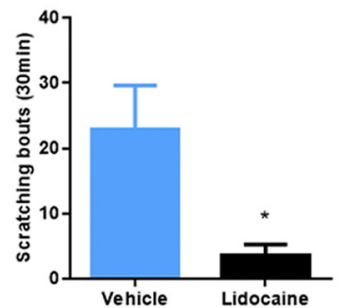

L

Biting Behavior (10 min)

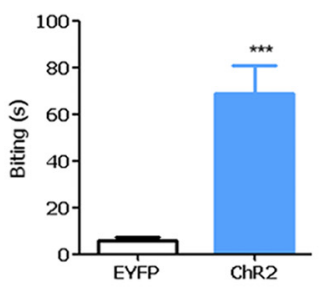

B
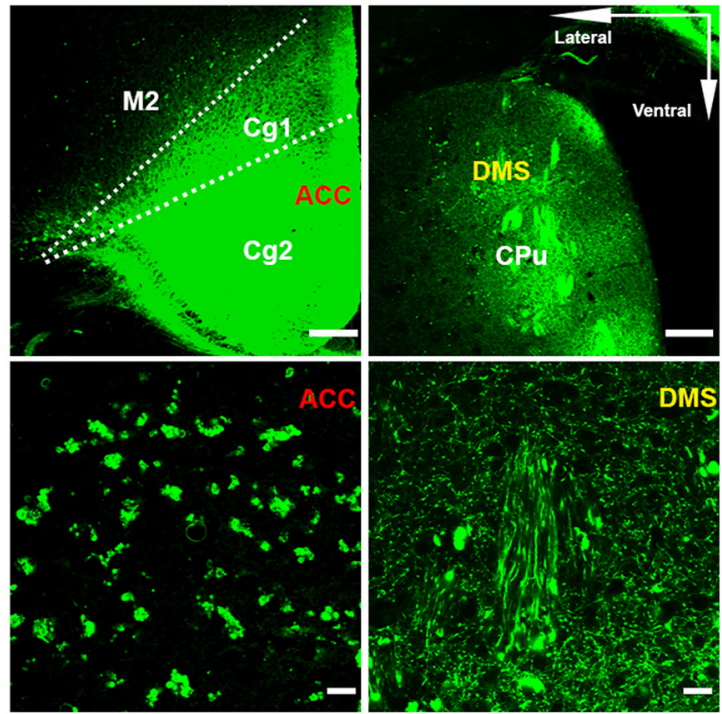

$\mathbf{F}$

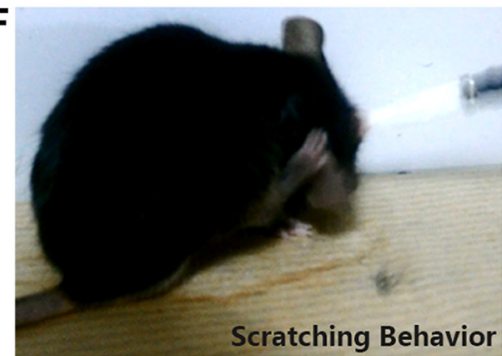

J
I

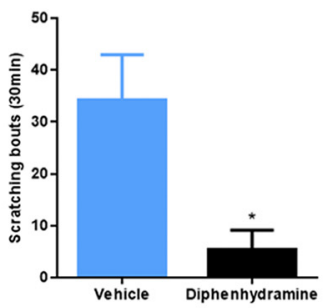

M

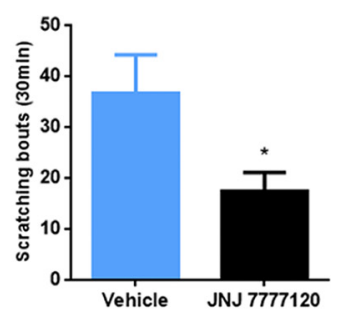

$\mathbf{N}$
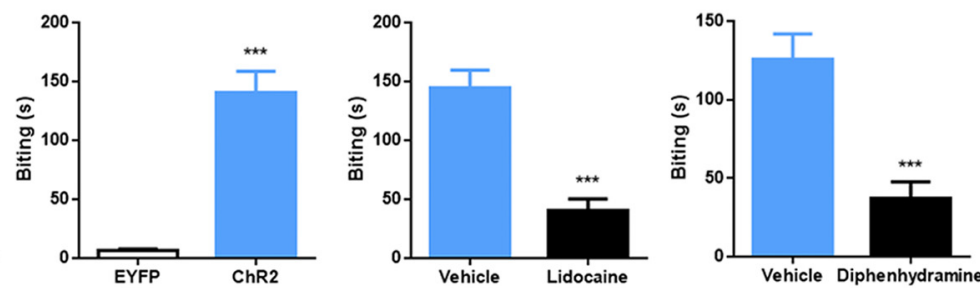

Figure 4. Photoactivation of ACC-DMS projections induces histamine-related behaviors of itch. $A$, Schematic illustration of injection of AAV carrying ChR2-EYFP into ACC and optical illumination of DMS. B, ChR2-EYFP expression in ACC and DMS. The images in the lower line exhibit ChR2-EYFP expression in the cell bodies of ACC (left) and neural fibers of DMS (right). Scale bars in the upper line, $200 \mu \mathrm{m}$; scale bars in the lower line, $50 \mu \mathrm{m}$. C, D, In vitro electrophysiological assessment of functional connectivity from ACC to DMS. Representative current-clamp traces from ACC somata (C) and ACC terminals in the DMS (D) obtained from 10 flashes of light illumination at $20 \mathrm{~Hz}$. E, Experiment paradigm of optical illumination and behavior test. Light illumination for 3 min, followed by $2 \mathrm{~min}$ of rest time without light illumination, and total six cycles for 30 min.F, G, Mice expressing ChR2-EYFP displayed scratching behavior after 30 min of repeated stimulation-rest cycles. Mice with photoactivation of ACC-DMS could unilaterally or bilaterally scratch the body sites of head, neck or abdomen. $t_{(16)}=2.367, p=0.0297$. H, Subcutaneous injection of $0.3 \%$ lidocaine (s.c., 200 $\mu$ l) significantly decreased scratching behavior induced by photoactivation of ACC-DMS. $t_{(15)}=2.612, p=0.0196 . I, J$, Intraperitoneal injection of diphenhydramine (H1Rs antagonist, $10 \mathrm{mg} / \mathrm{kg}$ ) and JNJ 7777120 (H4Rs antagonist, $15 \mathrm{mg} / \mathrm{kg}$ ) greatly attenuated scratching behavior. $I, t_{(14)}=2.715, p=0.0168 . J, t_{(14)}=2.233, p=0.0424 . K, L$, Mice expressing ChR2-EYFP exhibited biting behavior after light illumination with $10 \mathrm{~min}$ or $30 \mathrm{~min}$ of stimulation-rest cycles. Mice with photoactivation of ACC-DMS could unilaterally or bilaterally bite the skin of back or hindlimbs. $L, t_{(14)}=$ 8.274. $\boldsymbol{M}, \boldsymbol{N}$, Both lidocaine (s.C., $0.3 \%, 200 \mu \mathrm{l})$ and diphenhydramine (i.p., $10 \mathrm{mg} / \mathrm{kg}$ ) significantly decreased biting behavior evoked by photoactivation of ACC-DMS. $\boldsymbol{M}, t_{(15)}=5.648 . N, t_{(13)}=$ $4.415, p=0.0007$. All data are shown as mean \pm SEM. ${ }^{*} p<0.05,{ }^{* * *} p<0.001$ compared with EYFP or vehicle control group, Student's $t$ test. $n=7-10$ mice for each group. 


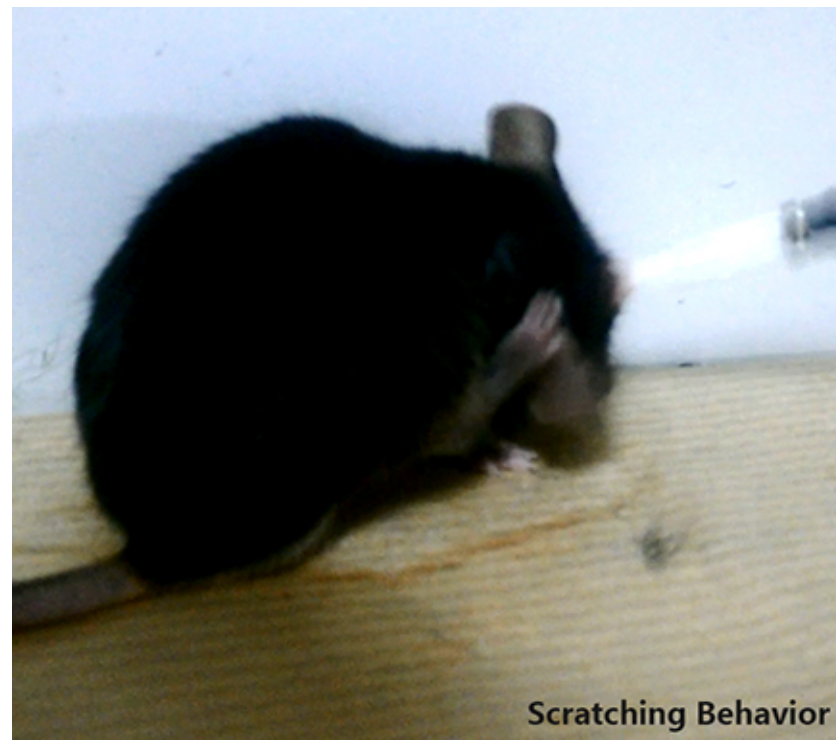

Movie 1. Increased scratching behavior induced by photoactivation of ACC-DMS projections (see Fig. 3).
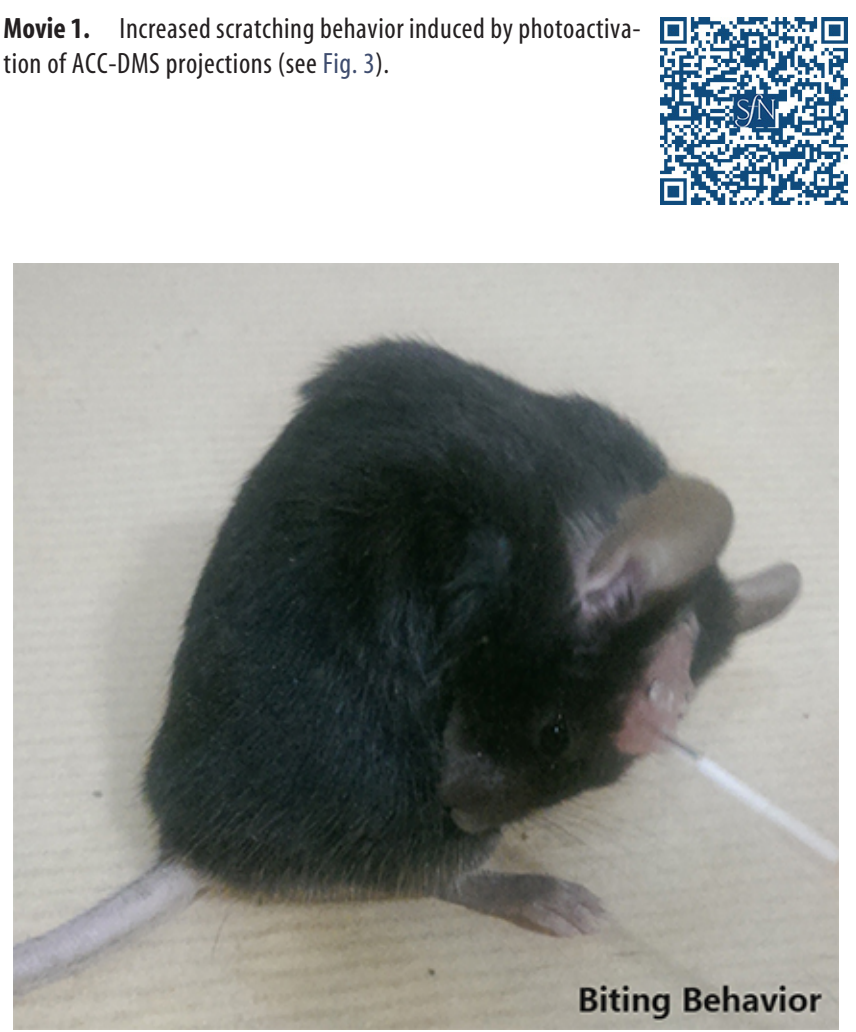

Movie 2. Increased biting behavior induced by photoactivation of ACC-DMS projections (see Fig. 3).

activated ACC differently by examining c-fos expression in response to histamine and 5-HT stimuli. We found that subcutaneous injection of histamine, but not 5-HT, into the nape of neck notably increased c-fos expression in the ACC (Fig. 6A,B), suggestive of histamine, but not 5-HT, activation of the ACC.

Pruritic information is thought to be integrated initially in the dorsal spinal cord. We thus examined the effects of histamine and 5 -HT on c-fos expression in the dorsal horn. Subcutaneous in- jection of histamine and 5-HT into the nape of neck both notably increased c-fos expression in the dorsal horn (Fig. 6C,D), supportive of a key role of the dorsal spinal cord in itch processing and suggesting that activation of the dorsal spinal cord is essential for both histamine- and 5-HT-induced itch sensation. Next, we investigated whether different modulation of histamine- and 5-HTinduced itch-related behavior by ACC-DMS projections was because ACC-DMS projections could exert a different regulatory effect on neuronal activities induced by histamine and 5-HT in the dorsal spinal cord. To this end, we tested the effect of photoinhibition of ACC-DMS projections on c-fos expression in the dorsal horn induced by histamine and 5-HT. We found that photoinhibition of ACC-DMS projections remarkably suppressed histamine-induced, but not 5-HT-induced, c-fos expression (Fig. $6 C, D$ ), suggesting that ACC-DMS projections modulate histamine-induced behavior of itch by acting on the dorsal spinal cord.

\section{Optogenetic manipulation of ACC-DMS projections has no effect on acute pain-related behaviors but modulates inflammatory pain responses}

The results mentioned above demonstrated that the mice with unilateral lesion of ACC plus contralateral lesion of DMS exhibited normal pain responses to mechanical, thermal, and chemical stimuli (Fig. 3). To further confirm the role of ACC-DMS projections in nociceptive responses, we examined the effects of photoactivation of ACC-DMS projections on pain responses induced by various noxious sensory stimuli. Mice expressing ChR2-EYFP or EYFP alone in ACC were exposed to thermal, mechanical, and inflammatory stimulation immediately after cycles of illumination above ACC terminals in DMS with $473 \mathrm{~nm}$ laser for $30 \mathrm{~min}$. When placed on a hotplate or receiving radiant-heat stimulation after received illumination, mice expressing ChR2-EYFP and EYFP alone responded with a similar latency (Fig. 7 $A, B$ ), indicating that thermal sensitivity is unchanged in the two groups. Similarly, in the paw pressure test, the mice in both groups also exhibited comparable mechanical pain responses (Fig. 7C).

Although photoactivation of ACC-DMS projections showed no significant changes in response to the thermal and mechanical nociceptive sensory assays, the formalin test was a marked exception. Although the two groups of mice displayed similar behavioral responses (primarily licking of the hindpaw) by injection of $5 \%$ formalin into the left hindpaw in the early phase (0-10 min), the mice expressing ChR2-EYFP exhibited dramatically lower pain responses in the late phase $(10-60 \mathrm{~min})$ compared with the mice expressing EYFP alone (Fig. 7D). The remarkable reduction of pain responses in the late phase may be due to an increased itch response, which antagonizes the formalin-induced pain response (Ikoma et al., 2006). The augmentation of the itch response in the late phase may result from activation of pruritoceptors by formalin-induced release of pruritogens (Tjølsen et al., 1992) and from photoactivation of ACC-DMS projections (Fig. 7E). A similar reduction of pain response by photoactivation of ACC-DMS projections was also observed in the CFA-induced inflammatory pain response (Fig. $7 F$ ). Together, these results suggest that ACC-DMS projections have no significant effect on acute pain responses, but attenuate pain responses induced by formalin in the late phase and CFA-induced pain.

It has been established that the cheek and calf models can be used to distinguish between pain and itch, in which, whereas scratching the cheek with the hindlimb and biting the skin of the calf are indicative of itch response, wiping the cheek by the forepaw and licking the skin of the calf are suggestive of pain response, respectively (Shimada and LaMotte, 2008; Akiyama et al., 2010; LaM- 
A

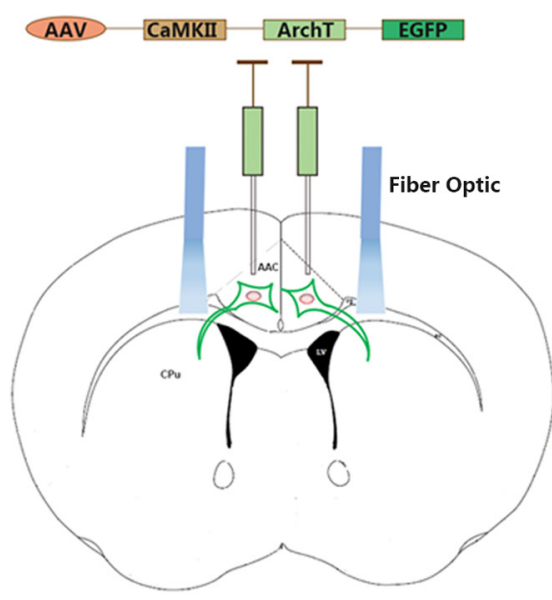

E

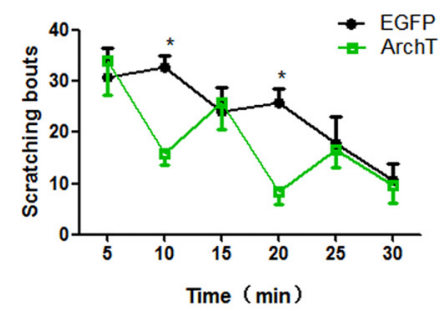

G

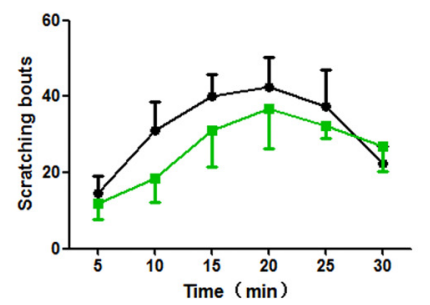

I

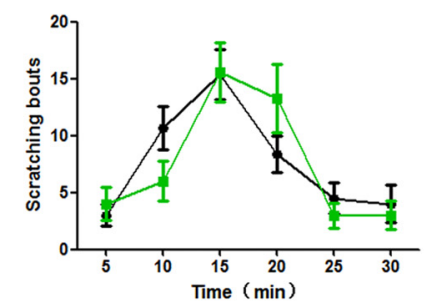

B

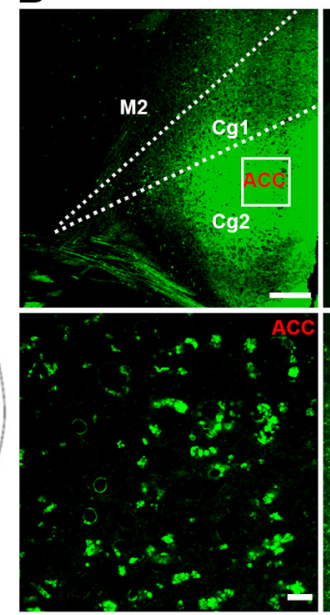

C
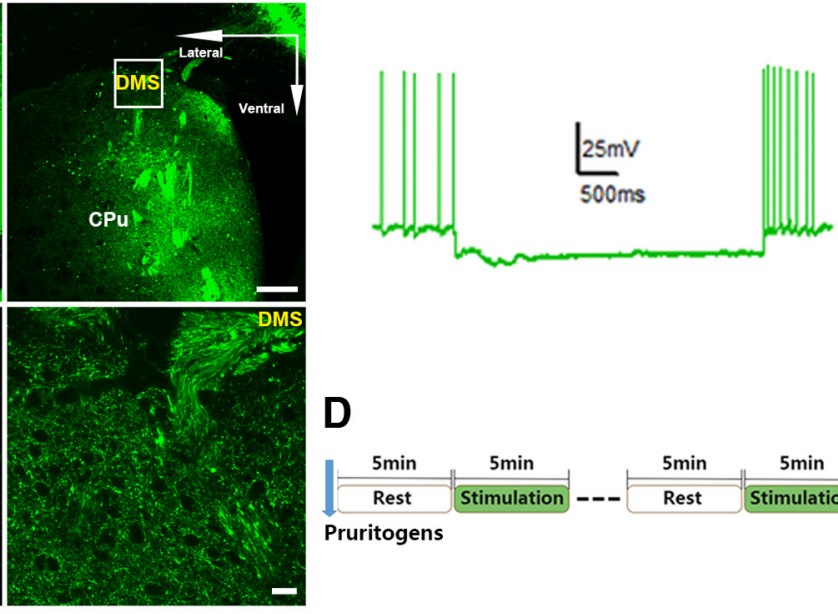

F

Compound 48/80 (neck)
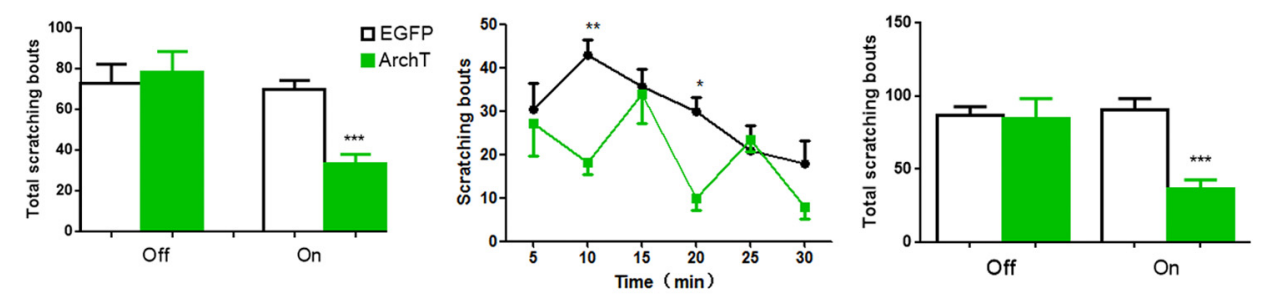

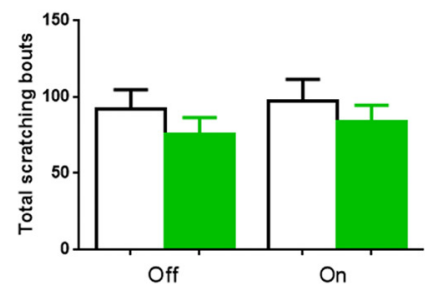

5-HT (cheek)

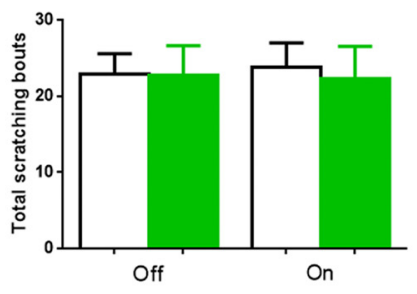

H

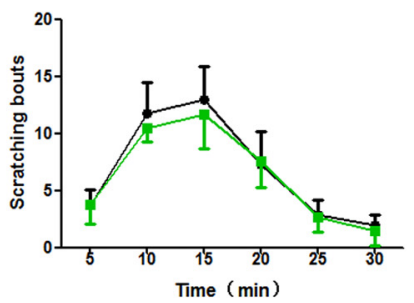

5-HT (neck)

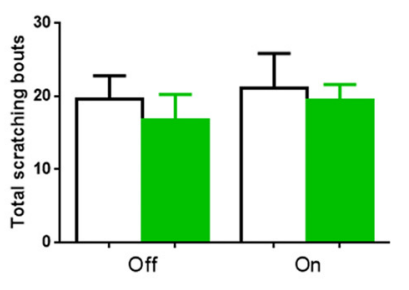

5-HT (calf)

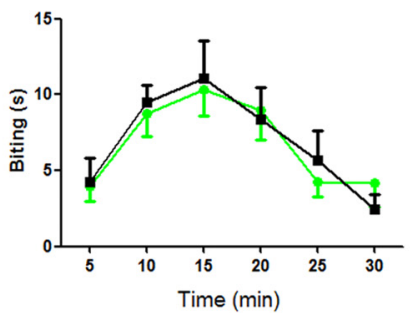

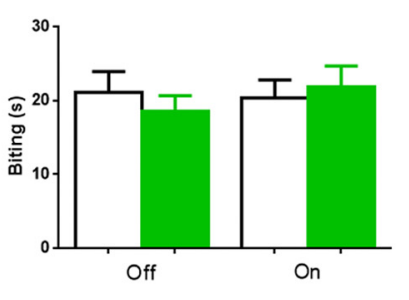

Figure 5. Photoinhibition of ACC-DMS projections decreases histamine-induced behaviors of itch. A, Schematic illustration of bilateral injection of AAV carrying ArchT-EGFP into the ACC and optical illumination of DMS. B, ArchT-EGFP expression in ACC and DMS. The images in the lower line exhibit ArchT-EGFP expression in the cell bodies of ACC (left) and neural fibers of DMS (right). Scale bars in the upper line, $200 \mu \mathrm{m}$; scale bars in the lower line, $50 \mu \mathrm{m}$. C, Representative current-clamp traces from ACC somata after light illumination of DMS. D, Experiment paradigm of light illumination and behavior test. Light illumination was provided for $5 \mathrm{~min}$, followed by $5 \mathrm{~min}$ of rest time without light illumination, total three cycles for $30 \mathrm{~min}$. $\boldsymbol{E}, \boldsymbol{F}$, Photoinhibition of ACC-DMS projections decreased histamine-induced ( $500 \mu \mathrm{g} / 50 \mu \mathrm{l}$, s.c.) and compound 48/80-induced (100 $\mu \mathrm{g} / 50 \mu \mathrm{l}$, s.c.) scratching behavior. $\boldsymbol{E}$, Interaction, $F_{(5,65)}=2.66$; time, $F_{(5,65)}=7.3 ;$ off, $p=$ $0.7102 ;$ on, $p=0.0001$. F, Interaction, $F_{(5,80)}=2.81 ;$ time, $F_{(5,80)}=6.09 ;$ off, $p=0.8688 ;$ on, $p<0.0001$. G, H, Photoinhibition of ACC-DMS projections had no effect on non-histamine-related pruritogens chloroquine-induced ( $200 \mu \mathrm{g} / 50 \mu \mathrm{l}$, s.c.) and 5-HT-induced ( $75 \mu \mathrm{g} / 50 \mu \mathrm{l}$, s.c.) scratching behavior $(p>0.05)$. $G$, Interaction, $F_{(5,70)}=0.35 ;$ time, $F_{(5,70)}=3.94 ;$ off, $p=0.3263 ;$ on, $p=0.4536 . H$, Interaction, $F_{(5,80)}=0.06 ;$ time, $F_{(5,80)}=9.29 ;$ off, $p=0.5636 ;$ on, $p=0.7712$. I, Photoinhibition of ACC-DMS did not affect the scratching behavior triggered by 5 -HT in the cheek model. 5 -HT $(15 \mu \mathrm{g} / 10 \mu \mathrm{l})$ was injected into the skin of cheek on the right side, which increased scratching behavior to the injected site. Interaction, $F_{(5,65)}=1.441$; time, $F_{(5,65)}=14.1 ;$ off, $p=$ $0.9728 ;$ on, $p=0.7848$. J, Biting behavior induced by 5 -HT was comparable in the calf model when ACC-DMS was photoinhibited. The 5 -HT ( $15 \mu \mathrm{g} / 10 \mu$ l) was injected into the calfskin of right side, which elicited biting behavior to the injected site. Interaction, $F_{(5,65)}=0.2371$; time, $F_{(5,65)}=6.663 ;$ off, $p=0.4823 ;$ on, $p=0.6924$. All data are shown as mean $\pm S E M$. ${ }^{*} p<0.05$, ${ }^{* *} p<0.01$, ${ }^{* * *} p<0.001$ compared with EGFP alone group. The time course of scratching bouts was analyzed by two-way ANOVA and the total scratching bouts was analyzed by Student's $t$ test. $n=7-8$ mice for each group. 
A

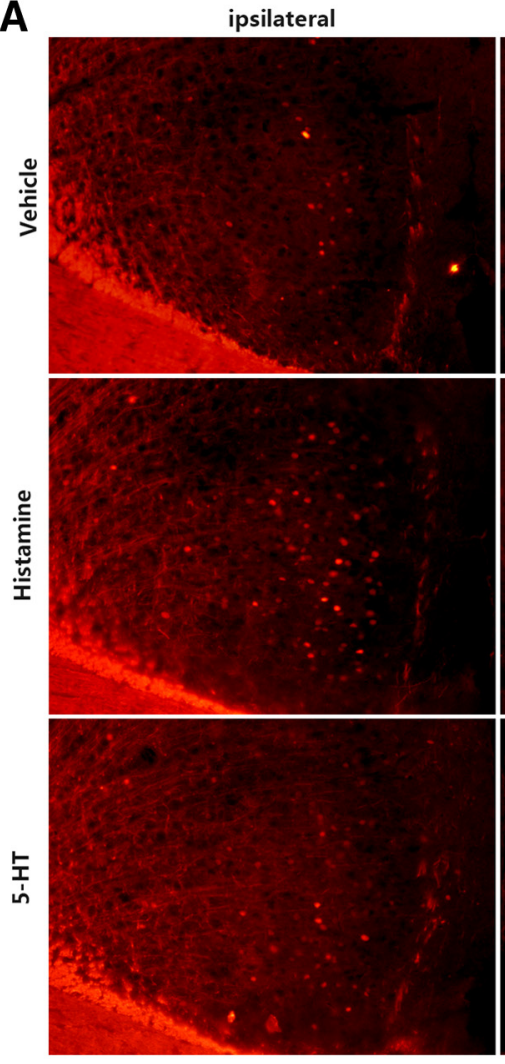

B

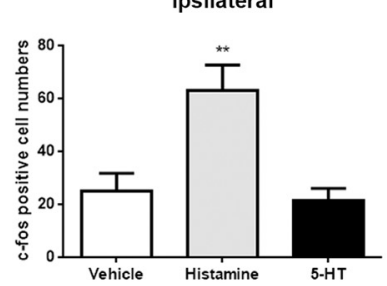

contralateral
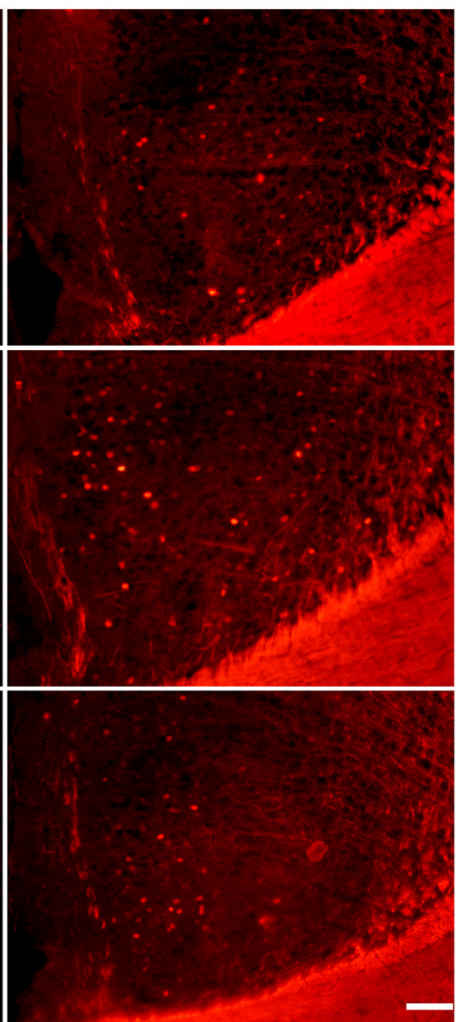

contralateral
C

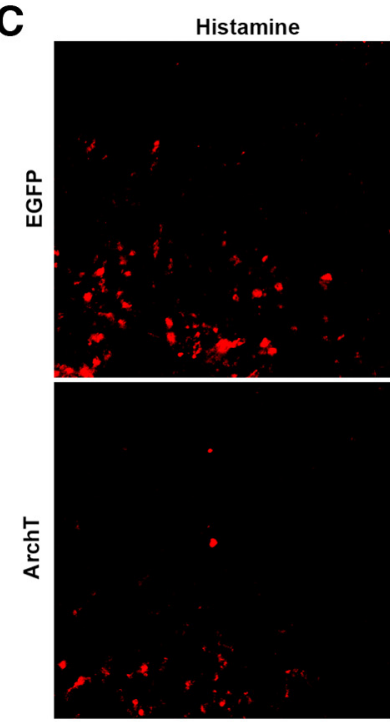

D

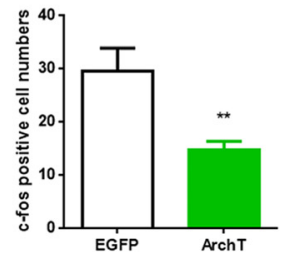

5-HT

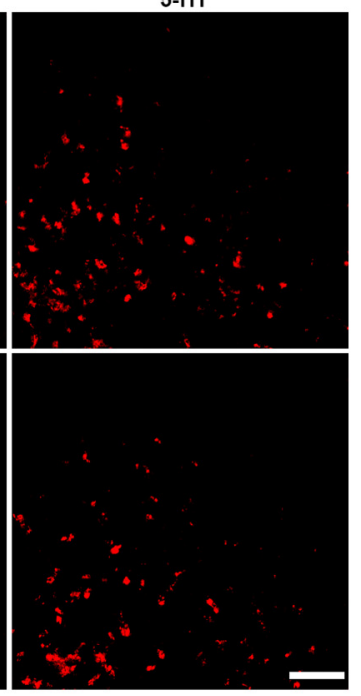

5-HT

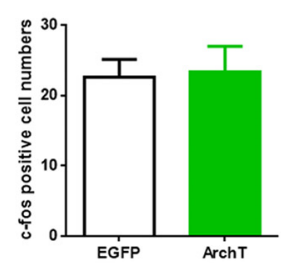

Figure 6. Histamine- and 5-HT-induced c-fos expression was differentially activated in ACC and inhibited in dorsal horn by photoinhibition of ACC-DMS. Mice were subcutaneously injected with histamine $(500 \mu \mathrm{g} / 50 \mu \mathrm{l})$ or 5 - $\mathrm{HT}(75 \mu \mathrm{g} / 50 \mu \mathrm{l})$ and c-fos expression was detected in the ACC or in the dorsal horn of spinal cord after 30 min cycles of ACC-DMS photoinhibition. $A$, Representative immunostaining images of c-fos expression in the bilateral ACC induced by pruritogens. Scale bar, $100 \mu \mathrm{m}$. $\boldsymbol{B}$, Quantification of immunostaining images of c-fos in the bilateral ACC. ipsilateral: histamine, $t_{(14)}=3.235, p=0.006 ; 5$-HT, $t_{(14)}=0.4516$; contralateral: histamine, $t_{(14)}=3.084, p=0.0081 ; 5$-HT, $t_{(14)}=0.4767$. C, Representative immunostaining images of c-fos expression in the dorsal horn induced by pruritogens when ACC-DMS was photoinhibited. Scale bar, $50 \mu \mathrm{m} . D$, Quantification of immunostaining images of $c$-fos in the dorsal horn. Histamine, $t_{(11)}=2.45, p=$ $0.0093 ; 5-H T, t_{(10)}=0.1865, p=0.8558$. Data are shown as mean \pm SEM. ${ }^{* *} p<0.01$ compared with the EGFP group or vehicle group, Student's $t$ test. $n=6-8$ mice for each group.

otte et al., 2011). Next, we used the cheek and calf models to confirm ACC-DMS projections' selective modulation of itch but not pain response. Intradermal injection of histamine into the cheek mainly induced scratching the site of injection with hindlimb, whereas intradermal injection of capsaicin mainly induced wiping the cheek with the forepaw. Photoinhibition of ACC-DMS projections significantly inhibited histamine-induced scratching behavior, although with no significant effect on wiping behavior induced by capsaicin (Fig. $8 A, B$ ). In the calf model, mice with histamine injection into the skin of the calf mainly exhibited biting behavior, whereas mice with capsaicin injection into the skin of the calf displayed licking behavior. Photoinhibition of ACC-DMS projections significantly reduced histamine-induced biting, but not capsaicin-induced, licking behaviors (Fig. $8 C, D$ ). These results further support that ACC-DMS projections are involved in modulation of itch and inflammatory pain response, but not pain response induced by thermal, mechanical, and chemical stimuli.

\section{Dorsal spinal cord exerts an inhibitory effect on itch signal from ACC-DMS projections through B5-I neurons}

The results mentioned above showed that photoinhibition of ACC-DMS projections attenuated histamine-stimulated c-fos expression in the dorsal horn (Fig. 6C,D), which suggests that interaction of ACC and the dorsal spinal cord may occur in itch and scratching processes. To further confirm the role of the dorsal spinal cord in ACC-DMS projections for modulation of itch and scratching processes (Fig. 9A), we first examined the effect of photoactivation of ACC-DMS projections on c-fos expression in the dorsal horn. We found that photoactivation of ACC-DMS projections significantly elevated c-fos expression in the dorsal horn (Fig. 9B,C). There are two populations of spinal interneurons that are specifically related to itch-related behavior. One type of interneurons express GRPR that are required for itch signal transmission (Sun and Chen, 2007; Sun et al., 2009). Intrathecal injection of the GRPR antagonist attenuated histamine- 
A

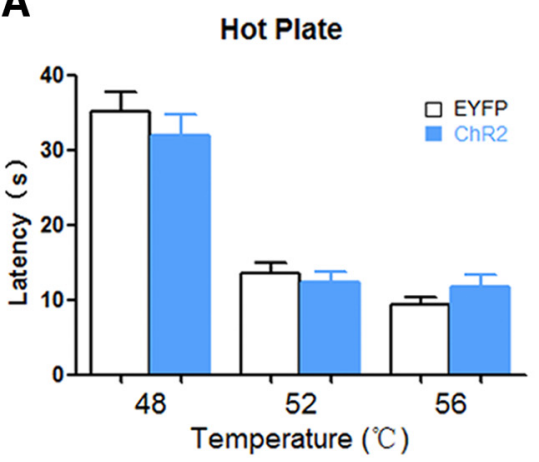

B

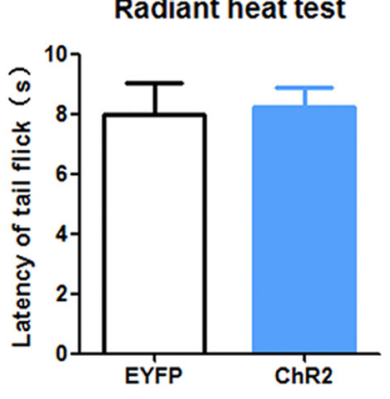

C

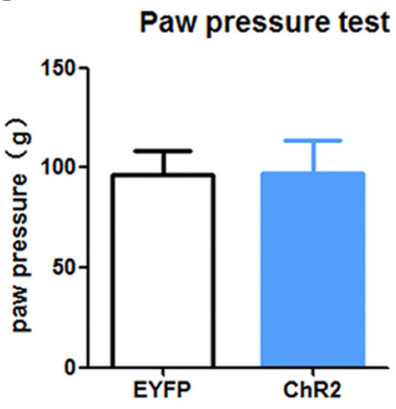

D

Formalin test
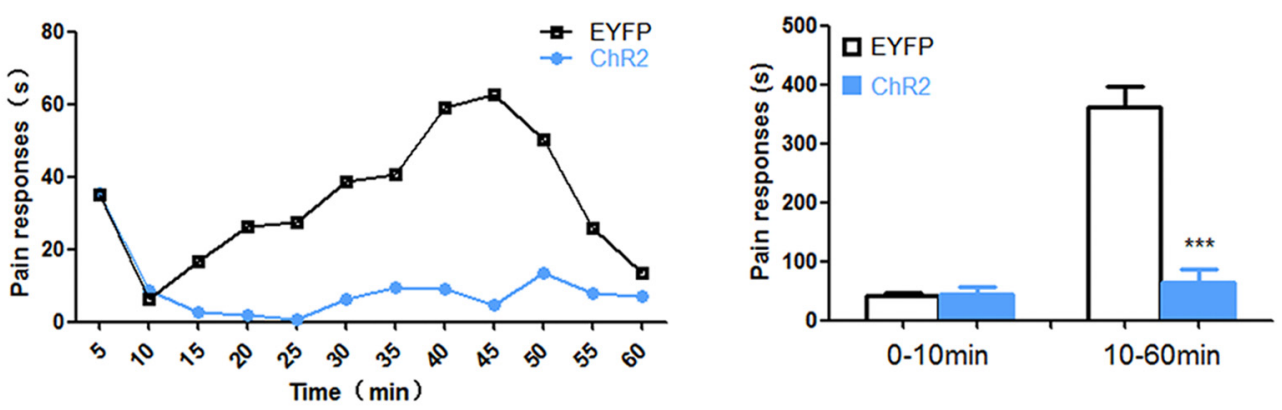

E

E Scratching Behavior

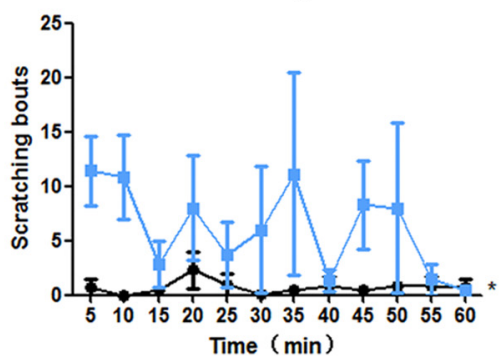

Biting Behavior

F

- EYFP
- ChR2

von Frey $(3 \mathrm{~h})$

von Frey (2 d)
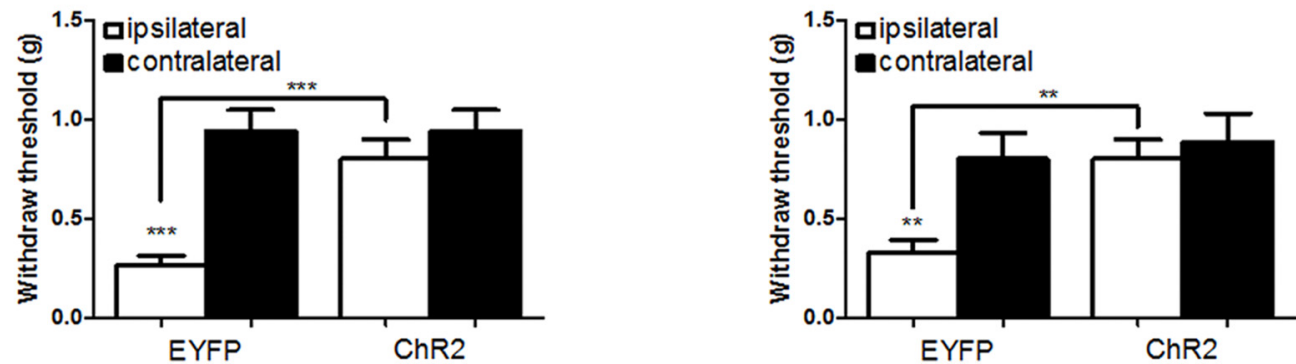

Figure 7. Photoactivation of ACC-DMS has no effect on acute pain sensation, but attenuates inflammatory pain responses. $\boldsymbol{A}, \boldsymbol{B}$, Mice expressing ChR2-EYFP and EYFP alone responded with a similar paw-withdrawal latency in thermal sensitivity tests $(p>0.05)$. Thermal pain responses were measured by hotplate $(\boldsymbol{A})$ and radiant heat $(\boldsymbol{B})$. Mice of two groups were illuminated by light before placed on hotplate and received radiant heat. $\boldsymbol{A}, 48^{\circ} \mathrm{C}, t_{(16)}=0.8695, p=0.3974 ; 52^{\circ} \mathrm{C}, t_{(16)}=0.6092, p=0.5510 ; 56^{\circ} \mathrm{C}, t_{(16)}=1.327, p=0.2032 . B, t_{(15)}=0.1687, p=0.8683 . \boldsymbol{C}$, Mice $_{1}$ expressing ChR2-EYFP and EYFP alone showed a comparable mechanical pain sensitivity after light illumination when measured by the paw pressure test $(p>0.05) . t_{(13)}=0.06667, p=0.9479$. D, Mice expressing ChR2-EYFP and EYFP alone showed a similar pain responses in the early phase (0-10 min) when formalin (5\%) was injected into the left hindpaw immediately after light illumination. However, during the late phase $(10-60 \mathrm{~min})$, mice expressing ChR2-EYFP exhibited significantly lower pain responses relative to mice only expressing EYFP: $0-10$ min, $t_{(13)}=0.2348$, $p=0.8180 ; 10-60 \mathrm{~min}, t_{(13)}=6.777, p<0.0001$. E, Prominent scratching and biting behaviors could be observed in $1 \mathrm{~h}$ after photoactivation of ACC-DMS. After 30 min of stimulation-rest cycles at $473 \mathrm{~nm}$, the scratching and biting behaviors were assessed immediately in the following $1 \mathrm{~h}$ per $5 \mathrm{~min}$ for the mice expressing EYFP or ChR2-EYFP. Scratching: interaction, $F_{(11,132)}=0.9323$; time, $F_{(11,132)}=0.8689 ; p=0.037$. Biting: interaction, $F_{(11,132)}=1.581 ;$ time, $F_{(11,132)}=1.396 ; p<0.0001$. $F$, Hyperalgesia evoked by intraplantar injection of CFA was attenuated after photoactivation of ACC-DMS. Mechanical sensitivity of $3 \mathrm{~h}$ and $2 \mathrm{~d}$ after CFA injection $(20 \mu \mathrm{l})$ into the left hindpaw was examined immediately for mice with or without photoactivation of ACC-DMS: $3 \mathrm{~h}$,

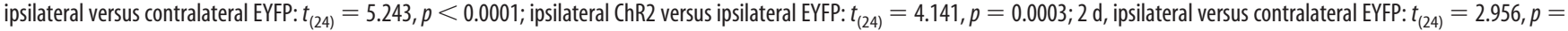
0.0069 ; ipsilateral ChR2 versus ipsilateral EYFP: $t_{(24)}=2.956, p=0.0016$. All data are shown as mean \pm SEM. $p>0.05,{ }^{*} p<0.05,{ }^{* *} p<0.01,{ }^{* * *} p<0.001$ compared with mice expressing EYFP or EGFP alone group. All data were analyzed by Student's $t$ test except for the figures that time course of pain responses in $\boldsymbol{D}-\boldsymbol{F}$ were analyzed by two-way ANOVA. $n=7-8$ mice for each group. 
A
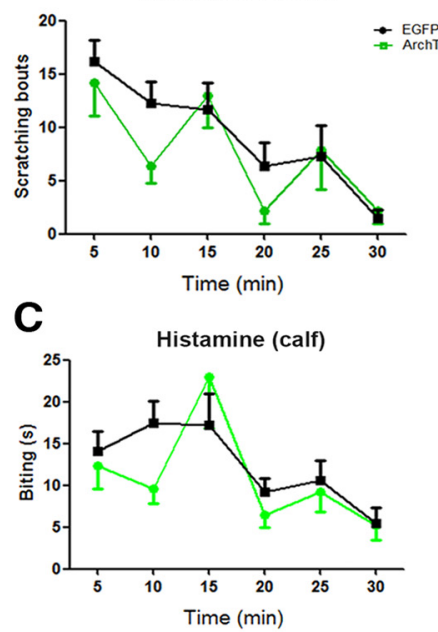

B
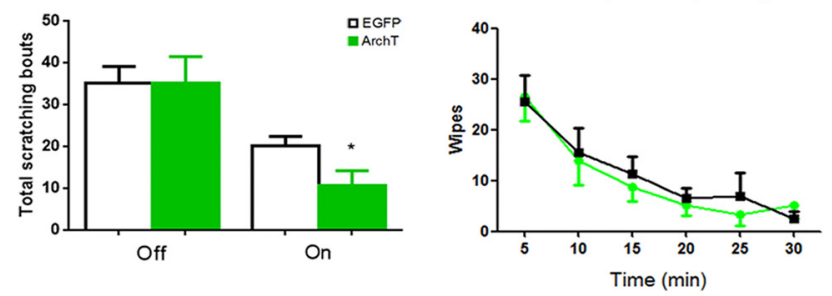

D

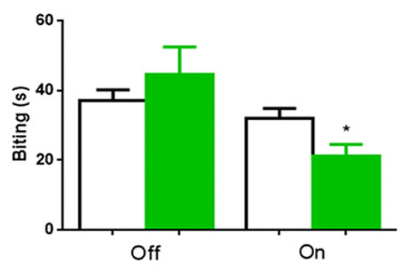

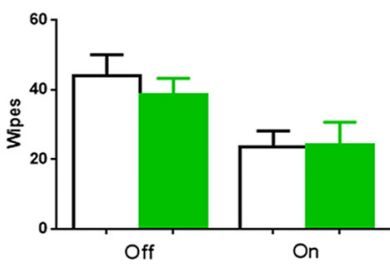
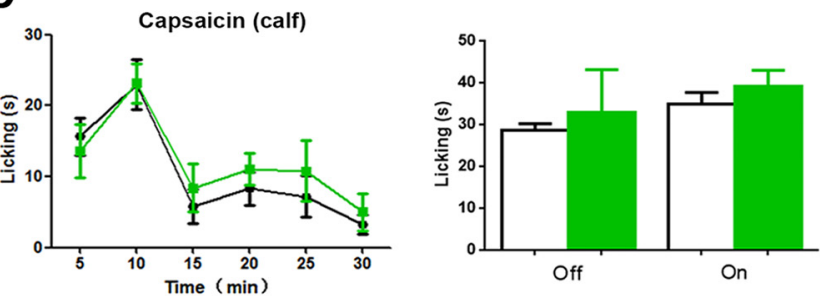

Figure 8. Photoinhibition of ACC-DMS selectively suppressed histamine-induced itch, but not capsaicin-induced pain. $A$, Photoinhibition of ACC-DMS attenuated scratching behavior response to itch induced by histamine $(100 \mu \mathrm{g} / 10 \mu \mathrm{l})$ in cheek model. Interaction, $F_{(5,70)}=0.825$; time, $F_{(5,70)}=9.158 ;$ off, $p=1 ; 0$ n, $p=0.0418$. $\boldsymbol{B}$, Pain-related wiping behavior induced by capsaicin (10 $\mu \mathrm{g} / 10 \mu \mathrm{l})$ was unaltered by ACC-DMS photoinhibition in the cheek model. Interaction, $F_{(5,70)}=0.1919 ;$ time, $F_{(5,70)}=9.879 ;$ off, $p=0.5017 ;$ on, $p=0.9375$. C, Photoinhibition of ACC-DMS reduced biting behavior response to itch elicited by histamine $(100 \mu \mathrm{g} / 10 \mu \mathrm{l})$ in the calf model. Interaction, $F_{(5,60)}=1.287$; time, $F_{(5,70)}=7.335 ;$ off, $p=0.3922 ;$ on, $p=0.0249$. D, Licking behavior response to pain sensation triggered by capsaicin $(10 \mu \mathrm{g} / 10 \mu \mathrm{l})$ was comparable in mice with ACC-DMS photoinhibition in calf model. Interaction, $F_{(5,60)}=0.2657$; time, $F_{(5,70)}=10.87$; off, $p=0.6959 ;$ on, $p=0.369$. All data are shown as mean \pm SEM. $p>0.05,{ }^{*} p<0.05$, compared with mice expressing EYFP or EGFP alone. The time courses of itch or pain responses were analyzed by two-way ANOVA and the total effects of itch or pain responses were analyzed by Student's $t$ test. $n=7-8$ mice for each group.

A

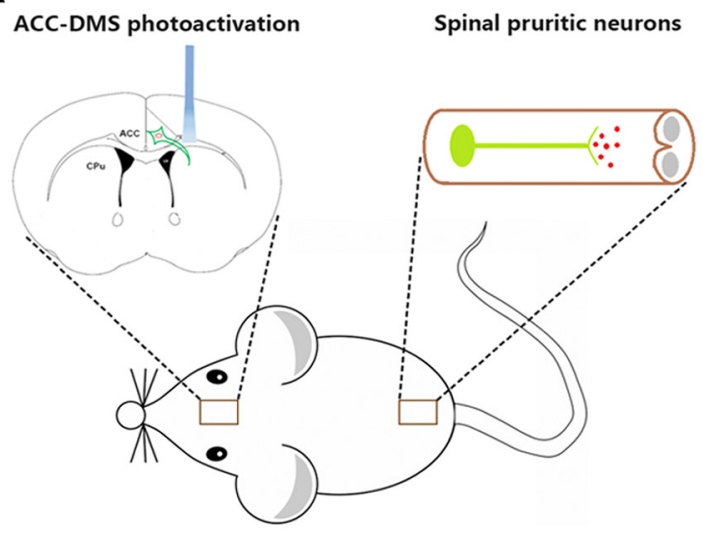

B

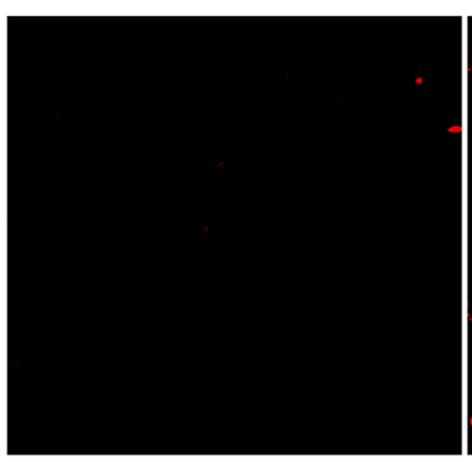

ChR2

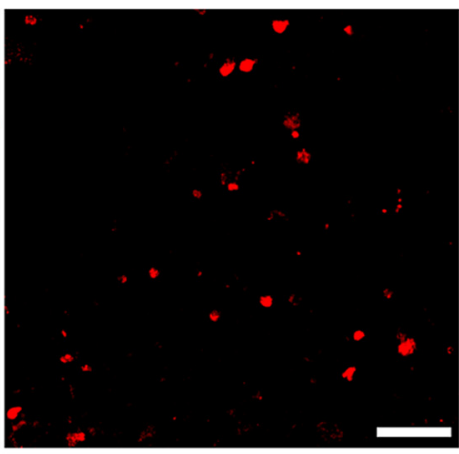

C

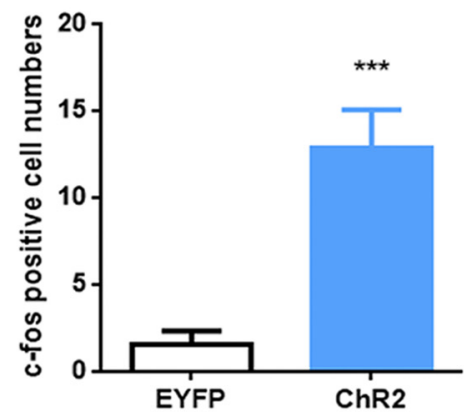

D
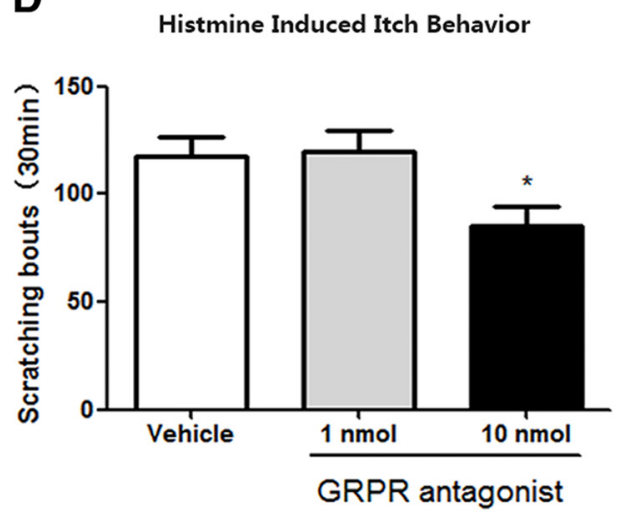

E

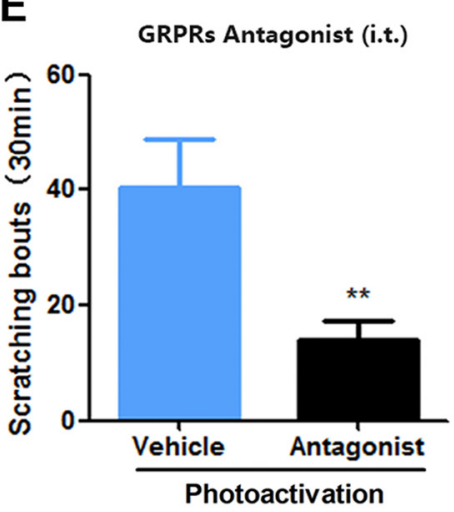

Figure 9. Itch signal descending from ACC-DMS projections is modulated by GRPRs in the spinal cord. $A$, Schematic illustration of ACC-DMS projections in brain and pruritic neurons in the spinal cord. $B, C$, Photoactivation of ACC-DMS elevated c-fos expression in the dorsal horn of spinal cord. $t_{(10)}=4.756, p=0.0008$. Scale bar, $50 \mu \mathrm{m}$. $\boldsymbol{D}$, Intrathecal injection of the GRPR antagonist $(10 \mathrm{nmol})$ significantly reduced scratching behavior evoked by histamine $(500 \mu \mathrm{g} / 50 \mu \mathrm{l}) . F_{(2,21)}=4.216 ; 10 \mathrm{nmol}, p=0.0289 . E$, GRPR antagonist significantly suppressed scratching behavior induced by photoactivation of ACC-DMS projections. Mice expressing ChR2-EYFP were injected with (D-Phe12, Leu14)-bombesin ( $10 \mathrm{nmol} / 5 \mu l$, i.t.) before being illuminated by light. $t_{(13)}=3.016$, $p=0.0099$. Data are shown as mean \pm SEM. ${ }^{*} p<0.05,{ }^{* *} p<0.01,{ }^{* * *} p<0.001$ compared with vehicle groups. Data in $\boldsymbol{C}$ and $\boldsymbol{E}$ were analyzed by Student's $t$ test and data in $\boldsymbol{D}$ were analyzed by one-way ANOVA. $n=6-8$ mice for each group. 
A

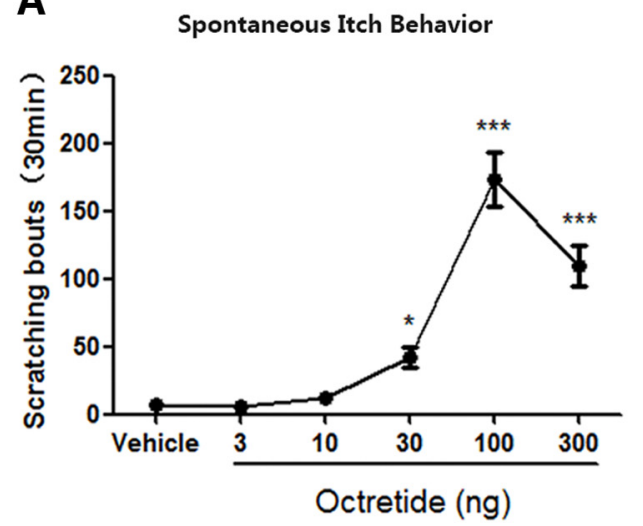

C

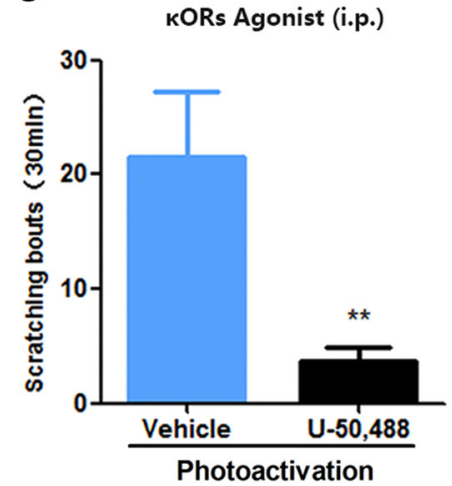

D

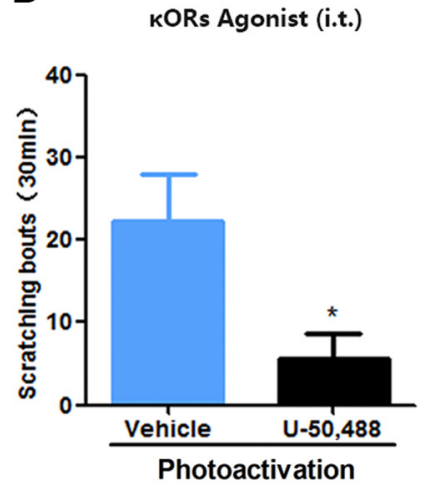

B

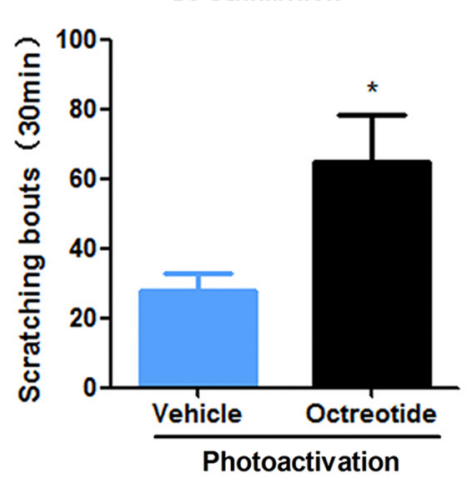

E

Figure 10. Itch mediated by ACC-DMS projections is suppressed by B5-I neurons in the spinal cord. $A$, Intrathecal administration of B5-I neurons inhibit octreotide dose dependently evoked spontaneous scratching behavior. $F_{(5,42)}=41.53$. B , Inhibition of B5-I neurons significantly increased scratching behavior induced by photoactivation of ACC-DMS injections. Mice expressing ChR2-EYFP were injected with somatostatin analog octreotide (10 ng/5 $\mu$ l, i.t.). $t_{(12)}=2.572, p=0.0245$. C, D, Systemic or intrathecal administration of the $\kappa 0$ R agonist U-50,488 inhibited scratching behavior induced by photoactivation of ACC-DMS projections. Mice expressing ChR2-EYFP were intraperitoneally (C) orintrathecally (D) injected with U-50,488 ( $2 \mathrm{mg} / \mathrm{kg}$ for i.p.; $10 \mu \mathrm{g} / 5$ $\mu$ l for i.t.) before being illuminated by light. $\boldsymbol{C}, t_{(14)}=3.465, p=0.0038 . \boldsymbol{D}, t_{(14)}=2.559, p=0.0227$. $\boldsymbol{E}$, Intrathecal administration of $\kappa 0$ R antagonist significantly enhanced scratching behavior induced by photoactivation of ACC-DMS projections. Mice expressing ChR2-EYFP were injected with norBNI $\left(1 \mu \mathrm{g} / 5 \mu\right.$ l, i.t.) before being illuminated by light. $t_{(13)}=2.29, p=0.0349$. Data are shown as mean \pm SEM. ${ }^{*} p<0.05,{ }^{* *} p<0.01,{ }^{* * *} p<0.001$ compared with vehicle groups. Data in $\boldsymbol{A}$ were analyzed by one-way ANOVA; data in $\boldsymbol{B}-\boldsymbol{E}$ were analyzed by Student's $t$ test. $n=6-8$ mice for each group.

induced scratching behavior (Fig. 9D). We thus tested the effect of GRPR antagonist on scratching behavior induced by photoactivation of ACC-DMS projections. Intrathecal injection of the GRPR antagonist (D-Phe12, Leu14)-bombesin suppressed photoactivation-induced scratching behavior (Fig. 9E), suggesting that itch signal from ACC-DMS projections is relayed by the dorsal spinal cord through GRPR.

In the spinal cord, the other type of interneurons termed B5-I neurons, which can be defined by their developmental expression of the transcription factor Bhlhb5, suppress itch but not pain signal transmission(Ross et al., 2010; Kardon et al., 2014). Consistent with previous studies (Seybold et al., 1982; Kardon et al., 2014), intrathecal administration of octreotide also dose dependently evoked spontaneous scratching behavior (Fig. 10A). Next, we determined whether B5-I neurons could exert an inhibitory effect on itch signal from ACC-DMS projections. Because the vast majority of B5-I neurons belong to the subset of inhibitory spinal interneurons that express the somatostatin receptor $\mathrm{sst}_{2 \mathrm{~A}}$ (Kardon et al., 2014), we thus detected the effect of intrathecal injection of the somatostatin analog octreotide on scratching behavior induced by photoactivation of ACC-DMS projections. Intrathecal administration of octreotide markedly increased scratching behavior induced by photoactivation of ACC-DMS projections (Fig. 10B). These results are consistent with a previous study (Kardon et al., 2014) and support that B5-I neurons can inhibit itch signal from ACC-DMS projections. The previous study showed that B5-I neurons inhibited itch-related behavior by releasing kappa opioid dynorphin (Kardon et al., 2014). We therefore determined the effects of the kappa opioid receptor $(\kappa \mathrm{OR})$ agonist U-50,488 or antagonist norBNI on itch-related behavior induced by photoactivation of ACC-DMS projections. We found that intraperitoneal and intrathecal injections of U-50,488 both significantly inhibited itch-related behavior induced by photoactivation of ACC-DMS projections (Fig. 10C,D). In contrast, intrathecal injection of norBNI significantly enhanced photoactivation-induced scratching behavior (Fig. 10E). These data confirm that B5-I neurons can exert an inhibitory effect on ACCDMS projections in itch modulation.

\section{Discussion}

Substantial evidence has shown that itch and scratch processing requires supraspinal structures (Yosipovitch et al., 2008; Mochizuki and Kakigi, 2015; Mochizuki et al., 2015). Among these structures, ACC and DMS have been consistently reported to be activated in functional brain-imaging studies of histamineinduced itch response (Leknes et al., 2007; Vierow et al., 2009; Papoiu et al., 2012). This suggests that ACC and DMS may constitute a neural circuit that processes histaminergic itch-related behavior. However, the precise functional connectivity between the ACC and DMS, as well as the role of this circuit in controlling histaminergic itch-related behavior, have not been described. 


\section{ACC-DMS projections mediate histaminergic, but not nonhistaminergic, itch-related behavior}

One major finding of the present study is that we have identified the ACC-DMS projections as a neural substrate for selective modulation of histaminergic itch-related behavior. This conclusion is supported by the following evidence. First, the neural tract tracing experiments demonstrate that the ACC has neural projections into the DMS and that ACC-DMS projections can be activated by histamine, which is indicated by the colocalization of histamine-induced c-fos and FG retrograde tracing from DMS in the ACC neurons, whereas the other somatosensory- and emotionrelated brain regions were not detected increasing c-fos exression after histamine stimulation. Second, circuit disconnection by unilateral lesion of ACC plus contralateral lesion of DMS reduces histamine-induced, but not 5-HT-induced, scratching behavior. Finally, optogenetic manipulations of ACC-DMS projections alter histaminergic-related, but not nonhistaminergic-related, behaviors of itch. Different involvement of ACC-DMS projections in modulation of the histamine- and nonhistamine pruritogeninduced itch response may be attributed to their distinct abilities to activate ACC-DMS projections.

One possible explanation for modulation of histaminergic but not nonhistaminergic itch by ACC-DMS projections is that this neuronal pathway may selectively process itch signal transmitted from histamine-selective spinothalamic tract (STT) neurons. Electrophysiological studies on itch show that histamine and nonhistaminergic cowhage elicit responses in separate populations of neurons in the STT neurons (Davidson et al., 2007, 2010, 2012). There are different neuronal pathways consisting of specialized primary afferent and spinal projection neurons for the transmission of histaminergic and nonhistaminergic itch signal (Davidson et al., 2007; Johanek et al., 2008; Namer et al., 2008). The histamine-selective spinal neurons form a distinct pathway projecting from lamina I of the spinal cord to the ventrocaudal part of the nucleus medialis dorsalis (MDvc) (Andrew and Craig, 2001). The MDvc has projections to the anterior cingulate and dorsal insular cortex (Musil and Olson, 1988; Yasui et al., 1988). Based on the selective connectivity of pruritic input, ACC-DMS projections could distinguish between histaminergic and nonhistaminergic information.

\section{ACC-DMS projections are implicated in inflammatory pain but not acute pain responses induced by thermal, mechanical and chemical stimuli}

Itch and pain are two distinct sensations but are closely related. There is much overlap in the neuronal cells, circuits, and some of the signaling molecules that transmit itch and pain (Davidson and Giesler, 2010; Liu and Ji, 2013). Mounting evidence shows that itch-responding neurons are also sensitive to pain stimuli (Liu et al., 2009; Patel and Dong, 2010; Klein et al., 2011). Peripheral C-fibers that are excited by histamine are also activated by several nociceptive compounds, including bradykinin and capsaicin (Schmelz et al., 2003). A population of neurons in the superficial and deep dorsal horn of rodent and primate spinal cord is excited by pruritic agents as well as by noxious mechanical, thermal, or chemical stimuli (Carstens, 1997; Jinks and Carstens, 2000; Simone et al., 2004). However, there is a subpopulation of neurons in STT that selectively transmit itch signal to the brain (Davidson et al., 2007). These studies suggest that supraspinal, but not peripheral and spinal, neurons might play a crucial role in distinguishing between pruritic and nociceptive information based on the selective connectivity of pruritic input. The present study demonstrates that ACC-DMS projections are selectively implicated

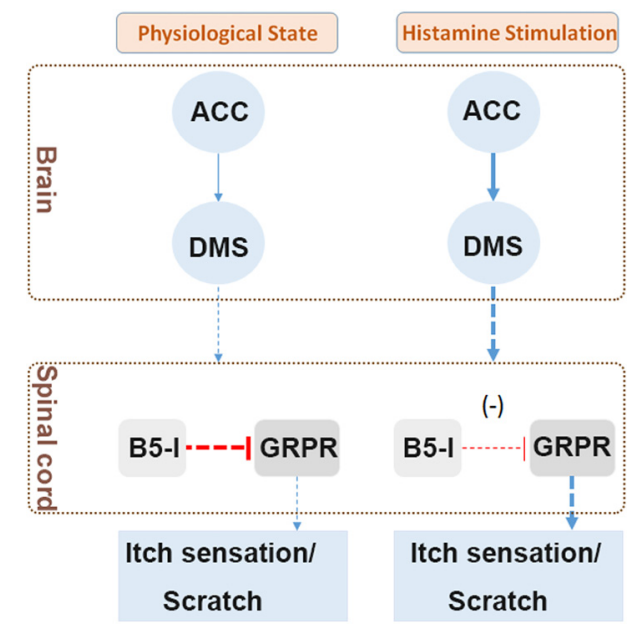

Figure 11. Proposed model for histamine-dependent itch modulation by interaction between the spinal cord and supraspinal regions. There may be two key itch modulation circuits in the mammalian. One is an excitatory circuit that locates cerebral area and is composed of ACC-DMS projections. This excitatory circuit may be responsible for the processing of itch sensation and the formation of motivation to trigger scratching behavior. The other one is an inhibitory circuit that locates the spinal cord and is composed of a specific population of inhibitory interneurons (B5-I neurons) that inhibit the itch signal from peripheral sensory neurons and the descending itch signal from supraspinal regions. In the physiological state, the functions of excitatory circuit and inhibitory circuit keep balance, so animals show no itch response to few existed endogenous pruritogens. However, in the pathological state or after receiving exogenous noxious stimulation, the excitatory circuit in the brain is overwhelmingly activated by released endogenous histamine, which results in the breakdown of functional balance. Therefore, animals will have an abnormal itch sensation, displaying scratching behavior that culminates in the development of skin lesions.

in modulation of itch but not pain response. We find that neither ACC-DMS circuit disconnection nor photoactivation of ACC-DMS projections had a significant effect on the pain behavior induced by noxious thermal, mechanical, and chemical stimuli. Photoactivation of ACC-DMS projections also fails to alter formalin-induced pain response in the early phase, but results in a markedly decreased pain response in the late phase of the formalin test. This may be due to increased itch response in the late phase resulting from activation of pruritoceptors by formalin-induced release of pruritogens (Tjølsen et al., 1992; Ross et al., 2010) and from photoactivation of ACCDMS projections. More importantly, in the cheek and calf models, photoinhibition of ACC-DMS projections significantly inhibited histamine-induced scratching and biting behaviors, with no significant effect on wiping and licking behaviors induced by capsaicin. Our findings provide convincing evidence that ACC-DMS projections are implicated in the modulation of itch and inflammatory pain but not acute pain responses.

\section{Interaction between the cerebral excitatory itch circuit and the spinal inhibitory itch circuit determines itch behavior} Another major finding of this study is that we have shown that the dorsal spinal cord exerts an inhibitory effect on itch signal from ACC-DMS projections through B5-I neurons, thereby revealing an interplay between the supraspinal and spinal levels in histaminergic itch regulation. First, photoactivation of ACC-DMS projections activates the dorsal spinal cord, as indicated by elevation of c-fos expression in the dorsal horn. Second, intrathecal administration of the GRPR antagonist significantly suppresses photoactivation of ACC-DMS projection-induced scratching behavior. Finally, manipulation of B5-I neurons function can alter photoactivation-induced scratching behavior. Potentiation of the B5-I neurons function by intrathecal administration of the 
$\kappa \mathrm{OR}$ agonist significantly suppressed photoactivation-induced scratching behavior, whereas attenuation of the B5-I neurons function by intrathecal administration of the $\kappa \mathrm{OR}$ antagonist or B5-I neuron inhibitor significantly enhanced photoactivationinduced scratching behavior.

Recent studies have reported that loss or suppression of inhibitory interneurons (B5-I neurons) in the dorsal spinal cord results in spontaneous itch response (Ross et al., 2010; Kardon et al., 2014) and this spontaneous itch response is abolished by local injection of lidocaine (Ross et al., 2010). These studies suggest that loss or suppression of B5-I neurons may induce the release of endogenous pruritogens in the periphery. In the present study, the observation that lidocaine and histamine receptor antagonist injections into the backs of mice abolished light-induced scratching behavior suggests that photoactivation of ACC-DMS projections caused activation of pruriceptors via increasing histamine release in the periphery. This may be due to photoactivation of ACC-DMS projection resulting in inhibition of inhibitory B5-I neurons in the dorsal spinal cord because inhibition of B5-I neurons by octreotide increased photoactivation of ACC-DMSinduced scratching behavior (Fig. 10B).

The present study, together with previous studies (Ross et al., 2010; Kardon et al., 2014), suggest that there are two functionally opposing itch modulation circuits in the rodents, namely the cerebral excitatory itch circuit and the spinal inhibitory itch circuit. The former is composed of the ACC-DMS projections, which amplifies itch signal input from peripheral sensory neurons. The latter is composed of a specific population of spinal inhibitory interneurons (B5-I neurons) in the dorsal horn, which inhibits itch signal from peripheral sensory neurons (Ross et al., 2010). Therefore, the counteractive interplay between the spinal inhibitory itch circuit and the cerebral excitatory itch circuit determines itch-related behavior and the balance between these two itch modulation circuits is crucial for regulating the normal manifestation of the itch response (Fig. 11). In the physiological state, due to lack of sufficient pruritogens, cerebral excitatory itch circuits are not activated and animals show no itch response to few pruritogens existing due to the role of the spinal inhibitory itch circuit. However, when the role of the spinal inhibitory itch circuit is overwhelmingly overcome by the hyperactivated cerebral excitatory itch circuit, as is seen in pathological states, or disinhibition of the spinal inhibitory itch circuit, as is seen in Bhlhb5 mutant mice (Ross et al., 2010; Kardon et al., 2014), animals will display persistent abnormal itch, resulting in a scratching response that culminates in the development of skin lesions.

According to the anterograde tracing results from Allen Mouse Brain Connectivity Atlas, DMS projects to brain regions including external globus pallidus, substantia nigra pars recitulata, and internal capsule, a white matter structure that contains corticospinal tract that mediates direct connections between the brain and the spinal cord (Jang, 2009). This may suggest that DMS projection is a direct descending pathway from ACC-DMS pathway to the spinal cord, but further studies will be required to address this critical issue.

\section{References}

Akiyama T, Carstens MI, Carstens E (2010) Differential itch- and painrelated behavioral responses and micro-opoid modulation in mice. Acta Derm Venereol 90:575-581. CrossRef Medline

Andrew D, Craig AD (2001) Spinothalamic lamina I neurons selectively sensitive to histamine: a central neural pathway for itch. Nat Neurosci 4:72-77. CrossRef Medline

Bautista DM, Wilson SR, Hoon MA (2014) Why we scratch an itch: the molecules, cells and circuits of itch. Nat Neurosci 17:175-182. CrossRef Medline
Cardinal RN, Parkinson JA, Hall J, Everitt BJ (2002) Emotion and motivation: the role of the amygdala, ventral striatum, and prefrontal cortex. Neurosci Biobehav Rev 26:321-352. CrossRef Medline

Carstens E (1997) Responses of rat spinal dorsal horn neurons to intracutaneous microinjection of histamine, capsaicin, and other irritants. J Neurophysiol 77:2499-2514. CrossRef Medline

Chow BY, Han X, Dobry AS, Qian X, Chuong AS, Li M, Henninger MA, Belfort GM, Lin Y, Monahan PE, Boyden ES (2010) High-performance genetically targetable optical neural silencing by light-driven proton pumps. Nature 463:98-102. CrossRef Medline

Darsow U, Drzezga A, Frisch M, Munz F, Weilke F, Bartenstein P, Schwaiger M, Ring J (2000) Processing of histamine-induced itch in the human cerebral cortex: a correlation analysis with dermal reactions. J Invest Dermatol 115:1029-1033. CrossRef Medline

Davidson S, Giesler GJ (2010) The multiple pathways for itch and their interactions with pain. Trends Neurosci 33:550-558. CrossRef Medline

Davidson S, Zhang X, Yoon CH, Khasabov SG, Simone DA, Giesler GJ Jr (2007) The itch-producing agents histamine and cowhage activate separate populations of primate spinothalamic tract neurons. J Neurosci 27: 10007-10014. CrossRef Medline

Davidson S, Truong H, Giesler GJ Jr (2010) Quantitative analysis of spinothalamic tract neurons in adult and developing mouse. J Comp Neurol 518:3193-3204. CrossRef Medline

Davidson S, Zhang X, Khasabov SG, Moser HR, Honda CN, Simone DA, Giesler GJ Jr (2012) Pruriceptive spinothalamic tract neurons: physiological properties and projection targets in the primate. J Neurophysiol 108:1711-1723. CrossRef Medline

Delgado MR, Stenger VA, Fiez JA (2004) Motivation-dependent responses in the human caudate nucleus. Cereb Cortex 14:1022-1030. CrossRef Medline

Drzezga A, Darsow U, Treede RD, Siebner H, Frisch M, Munz F, Weilke F, Ring J, Schwaiger M, Bartenstein P (2001) Central activation by histamine-induced itch: analogies to pain processing: a correlational analysis of O-15 H2O positron emission tomography studies. Pain 92:295305. CrossRef Medline

Dunford PJ, Williams KN, Desai PJ, Karlsson L, McQueen D, Thurmond RL (2007) Histamine H4 receptor antagonists are superior to traditional antihistamines in the attenuation of experimental pruritus. J Allergy Clin Immunol 119:176-183. CrossRef Medline

Gong D, Geng C, Jiang L, Cao J, Yoshimura H, Zhong L (2009) Effects of hydroxytyrosol-20 on carrageenan-induced acute inflammation and hyperalgesia in rats. Phytother Res 23:646-650. CrossRef Medline

Hadland KA, Rushworth MF, Gaffan D, Passingham RE (2003) The anterior cingulate and reward-guided selection of actions. J Neurophysiol 89:1161-1164. CrossRef Medline

Hassani OK, Cromwell HC, Schultz W (2001) Influence of expectation of different rewards on behavior-related neuronal activity in the striatum. J Neurophysiol 85:2477-2489. CrossRef Medline

Herde L, Forster C, Strupf M, Handwerker HO (2007) Itch induced by a novel method leads to limbic deactivations a functional MRI study. J Neurophysiol 98:2347-2356. CrossRef Medline

Hollerman JR, Tremblay L, Schultz W (2000) Involvement of basal ganglia and orbitofrontal cortex in goal-directed behavior. Prog Brain Res 126: 193-215. CrossRef Medline

Holstege JC, de Graaff W, Hossaini M, Cardona Cano S, Jaarsma D, van den Akker E, Deschamps J (2008) Loss of Hoxb8 alters spinal dorsal laminae and sensory responses in mice. Proc Natl Acad Sci U S A 105:6338-6343. CrossRef Medline

Hsieh JC, Hägermark O, ${ }^{*}$ Ståhle-Bäckdahl M, Ericson K, Eriksson L, StoneElander S, Ingvar M (1994) Urge to scratch represented in the human cerebral cortex during itch. J Neurophysiol 72:3004-3008. CrossRef Medline

Ikoma A, Steinhoff M, Ständer S, Yosipovitch G, Schmelz M (2006) The neurobiology of itch. Nat Rev Neurosci 7:535-547. CrossRef Medline

Jang SH (2009) A review of corticospinal tract location at corona radiata and posterior limb of the internal capsule in human brain. NeuroRehabilitation 24:279-283. CrossRef Medline

Jinks SL, Carstens E (2000) Superficial dorsal horn neurons identified by intracutaneous histamine: chemonociceptive responses and modulation by morphine. J Neurophysiol 84:616-627. CrossRef Medline

Johanek LM, Meyer RA, Friedman RM, Greenquist KW, Shim B, Borzan J, Hartke T, LaMotte RH, Ringkamp M (2008) A role for polymodal C-fiber 
afferents in nonhistaminergic itch. J Neurosci 28:7659-7669. CrossRef Medline

Kardon AP, Polgár E, Hachisuka J, Snyder LM, Cameron D, Savage S, Cai X, Karnup S, Fan CR, Hemenway GM, Bernard CS, Schwartz ES, Nagase H, Schwarzer C, Watanabe M, Furuta T, Kaneko T, Koerber HR, Todd AJ, Ross SE (2014) Dynorphin acts as a neuromodulator to inhibit itch in the dorsal horn of the spinal cord. Neuron 82:573-586. CrossRef Medline

Kim DK, Kim HJ, Kim H, Koh JY, Kim KM, Noh MS, Kim JJ, Lee CH (2008) Involvement of serotonin receptors 5-HT1 and 5-HT2 in 12(S)-HPETEinduced scratching in mice. Eur J Pharmacol 579:390-394. CrossRef Medline

Klein A, Carstens MI, Carstens E (2011) Facial injections of pruritogens or algogens elicit distinct behavior responses in rats and excite overlapping populations of primary sensory and trigeminal subnucleus caudalis neurons. J Neurophysiol 106:1078-1088. CrossRef Medline

Kunishio K, Haber SN (1994) Primate cingulostriatal projection: limbic striatal versus sensorimotor striatal input. J Comp Neurol 350:337-356. CrossRef Medline

Kuraishi Y, Nagasawa T, Hayashi K, Satoh M (1995) Scratching behavior induced by pruritogenic but not algesiogenic agents in mice. Eur J Pharmacol 275:229-233. CrossRef Medline

LaMotte RH, Shimada SG, Sikand P (2011) Mouse models of acute, chemical itch and pain in humans. Exp Dermatol 20:778-782. CrossRef Medline

Lauwereyns J, Watanabe K, Coe B, Hikosaka O (2002) A neural correlate of response bias in monkey caudate nucleus. Nature 418:413-417. CrossRef Medline

Leknes SG, Bantick S, Willis CM, Wilkinson JD, Wise RG, Tracey I (2007) Itch and motivation to scratch: an investigation of the central and peripheral correlates of allergen- and histamine-induced itch in humans. J Neurophysiol 97:415-422. CrossRef Medline

Liu Q, Tang Z, Surdenikova L, Kim S, Patel KN, Kim A, Ru F, Guan Y, Weng HJ, Geng Y, Undem BJ, Kollarik M, Chen ZF, Anderson DJ, Dong X (2009) Sensory neuron-specific GPCR mrgprs are itch receptors mediating chloroquine-induced pruritus. Cell 139:1353-1365. CrossRef Medline

Liu T, Ji RR (2013) New insights into the mechanisms of itch: are pain and itch controlled by distinct mechanisms? Pflugers Archiv 465:1671-1685. CrossRef Medline

Matsumoto K, Suzuki W, Tanaka K (2003) Neuronal correlates of goalbased motor selection in the prefrontal cortex. Science 301:229-232. CrossRef Medline

Mattis J, Tye KM, Ferenczi EA, Ramakrishnan C, O'Shea DJ, Prakash R, Gunaydin LA, Hyun M, Fenno LE, Gradinaru V, Yizhar O, Deisseroth K (2011) Principles for applying optogenetic tools derived from direct comparative analysis of microbial opsins. Nat Methods 9:159-172. CrossRef Medline

Mishra SK, Hoon MA (2013) The cells and circuitry for itch responses in mice. Science 340:968-971. CrossRef Medline

Mochizuki H, Kakigi R (2015) Central mechanisms of itch. Clin Neurophysiol 126:1650-1660. CrossRef Medline

Mochizuki H, Tashiro M, Kano M, Sakurada Y, Itoh M, Yanai K (2003) Imaging of central itch modulation in the human brain using positron emission tomography. Pain 105:339-346. CrossRef Medline

Mochizuki H, Tanaka S, Morita T, Wasaka T, Sadato N, Kakigi R (2014) The cerebral representation of scratching-induced pleasantness. J Neurophysiol 111:488-498. CrossRef Medline

Mochizuki H, Papoiu ADP, Nattkemper LA, Lin AC, Kraft RA, Coghill RC, Yosipovitch G (2015) Scratching induces overactivity in motor-related regions and reward system in chronic itch patients. J Invest Dermatol 135:2814-2823. CrossRef Medline

Morecraft RJ, Van Hoesen GW (1998) Convergence of limbic input to the cingulate motor cortex in the rhesus monkey. Brain Res Bull 45:209-232. CrossRef Medline

Musil SY, Olson CR (1988) Organization of cortical and subcortical projections to anterior cingulate cortex in the cat. J Comp Neurol 272:203-218. CrossRef Medline

Namer B, Carr R, Johanek LM, Schmelz M, Handwerker HO, Ringkamp M (2008) Separate peripheral pathways for pruritus in man. J Neurophysiol 100:2062-2069. CrossRef Medline

Napadow V, Li A, Loggia ML, Kim J, Schalock PC, Lerner E, Tran TN, Ring J, Rosen BR, Kaptchuk TJ, Pfab F (2014) The brain circuitry mediating antipruritic effects of acupuncture. Cereb Cortex 24:873-882. CrossRef Medline

Papoiu AD, Coghill RC, Kraft RA, Wang H, Yosipovitch G (2012) A tale of two itches: common features and notable differences in brain activation evoked by cowhage and histamine induced itch. Neuroimage 59:36113623. CrossRef Medline

Papoiu AD, Nattkemper LA, Sanders KM, Kraft RA, Chan YH, Coghill RC, Yosipovitch G (2013) Brain's reward circuits mediate itch relief. a functional MRI study of active scratching. PLoS One 8:e82389. CrossRef Medline

Patel KN, Dong X (2010) An itch to be scratched. Neuron 68:334-339. CrossRef Medline

Paus T (2001) Primate anterior cingulate cortex: where motor control, drive and cognition interface. Nat Rev Neurosci 2:417-424. CrossRef Medline

Ross SE, et al. (2010) Loss of inhibitory interneurons in the dorsal spinal cord and elevated itch in Bhlhb5 mutant mice. Neuron 65:886-898. CrossRef Medline

Rushworth MF, Walton ME, Kennerley SW, Bannerman DM (2004) Action sets and decisions in the medial frontal cortex. Trends Cogn Sci 8:410417. CrossRef Medline

Schmelz M, Schmidt R, Weidner C, Hilliges M, Torebjork HE, Handwerker HO (2003) Chemical response pattern of different classes of C-nociceptors to pruritogens and algogens. J Neurophysiol 89:2441-2448. CrossRef Medline

Seybold VS, Hylden JL, Wilcox GL (1982) Intrathecal substance P and somatostatin in rats: behaviors indicative of sensation. Peptides 3:49-54. CrossRef Medline

Shimada SG, LaMotte RH (2008) Behavioral differentiation between itch and pain in mouse. Pain 139:681-687. CrossRef Medline

Simone DA, Zhang X, Li J, Zhang JM, Honda CN, LaMotte RH, Giesler GJ Jr (2004) Comparison of responses of primate spinothalamic tract neurons to pruritic and algogenic stimuli. J Neurophysiol 91:213-222. CrossRef Medline

Sun YG, Chen ZF (2007) A gastrin-releasing peptide receptor mediates the itch sensation in the spinal cord. Nature 448:700-703. CrossRef Medline

Sun YG, Zhao ZQ, Meng XL, Yin J, Liu XY, Chen ZF (2009) Cellular basis of itch sensation. Science 325:1531-1534. CrossRef Medline

Thurmond RL, Gelfand EW, Dunford PJ (2008) The role of histamine H1 and $\mathrm{H} 4$ receptors in allergic inflammation: the search for new antihistamines. Nat Rev Drug Discov 7:41-53. CrossRef Medline

Tjølsen A, Berge OG, Hunskaar S, Rosland JH, Hole K (1992) The formalin test: an evaluation of the method. Pain 51:5-17. CrossRef Medline

Tye KM, Prakash R, Kim SY, Fenno LE, Grosenick L, Zarabi H, Thompson KR, Gradinaru V, Ramakrishnan C, Deisseroth K (2011) Amygdala circuitry mediating reversible and bidirectional control of anxiety. Nature 471:358-362. CrossRef Medline

Vierow V, Fukuoka M, Ikoma A, Dörfler A, Handwerker HO, Forster C (2009) Cerebral representation of the relief of itch by scratching. J Neurophysiol 102:3216-3224. CrossRef Medline

Walter B, Sadlo MN, Kupfer J, Niemeier V, Brosig B, Stark R, Vaitl D, Gieler U (2005) Brain activation by histamine prick test-induced itch. J Invest Dermatol 125:380-382. CrossRef Medline

Walton ME, Devlin JT, Rushworth MF (2004) Interactions between decision making and performance monitoring within prefrontal cortex. Nat Neurosci 7:1259-1265. CrossRef Medline

Xu YQ, Jin SJ, Liu N, Li YX, Zheng J, Ma L, Du J, Zhou R, Zhao CJ, Niu Y, Sun $\mathrm{T}$, Yu JQ (2014) Aloperine attenuated neuropathic pain induced by chronic constriction injury via anti-oxidation activity and suppression of the nuclear factor kappa B pathway. Biochem Biophys Res Commun 451:568-573. CrossRef Medline

Yasui Y, Itoh K, Kamiya H, Ino T, Mizuno N (1988) Cingulate gyrus of the cat receives projection fibers from the thalamic region ventral to the ventral border of the ventrobasal complex. J Comp Neurol 274:91-100. CrossRef Medline

Yin HH, Knowlton BJ, Balleine BW (2005) Blockade of NMDA receptors in the dorsomedial striatum prevents action-outcome learning in instrumental conditioning. Eur J Neurosci 22:505-512. CrossRef Medline

Yosipovitch G, Ishiuji Y, Patel TS, Hicks MI, Oshiro Y, Kraft RA, Winnicki E, Coghill RC (2008) The brain processing of scratching. J Invest Dermatol 128:1806-1811. CrossRef Medline

Zhang F, Aravanis AM, Adamantidis A, de Lecea L, Deisseroth K (2007) Circuit-breakers: optical technologies for probing neural signals and systems. Nat Rev Neurosci 8:577-581. CrossRef Medline

Zhang F, Gradinaru V, Adamantidis AR, Durand R, Airan RD, de Lecea L, Deisseroth K (2010) Optogenetic interrogation of neural circuits: technology for probing mammalian brain structures. Nat Protoc 5:439-456. CrossRef Medline 